\title{
COMPARATIVE ANALYSIS OF BODY COMPOSITION AND \\ REFERENCE VALUES OF VISCERAL ADIPOSE TISSUES IN VARIOUS AMERICAN COLLEGIATE SPORTS
}

\author{
A Thesis \\ Presented to \\ the Faculty of California Polytechnic State University, \\ San Luis Obispo
}

In Partial Fulfillment

of the Requirements for the Degree

Master of Science in Nutrition

By

Eshan Manoj Dandekar

September 2018 
(C) 2018

Eshan Manoj Dandekar ALL RIGHTS RESERVED 
COMMITTEE MEMBERSHIP

TITLE: Comparative Analysis of Body

Composition and Reference Values of

Visceral Adipose Tissues in Various

American Collegiate Sports

AUTHOR: $\quad$ Eshan Manoj Dandekar

DATE SUBMITTED: September 2018

COMMITTE CHAIR: $\quad$ Scott Reaves, Ph.D.

Professor of Nutrition

COMMITEE MEMBER: $\quad$ Kari Pilolla, Ph.D., R.D.,

Assistant Professor of Nutrition

COMMITTE MEMBER: Mary K. Oates, M.D.,

Physician, Santa Maria 


\begin{abstract}
Comparative Analysis of Body Composition and Reference Values of Visceral Adipose Tissues in Various American Collegiate Sports
\end{abstract}

Eshan Manoj Dandekar

Background: Currently, body composition (BC) assessment is usually performed to diagnose disease states and accurately estimate certain types of tissues. In athletes, performing BC assessments helps gauge training and nutrition programs to see if they are adequately meeting the athlete's needs to improve performance. Annual Dual Energy X-ray Absorptiometry (DXA) scans before the start of an athlete's season can help identify an athlete's preparedness or health before training begins.

Objective: To assess the preseason BC of four collegiate sports: Men's basketball, men's baseball, women's volleyball, and women's soccer, for Fat Mass (FM), bone mineral density BMD), Fat-Free Mass (FFM), and visceral adipose tissue (VAT).

Methods: DXA (Lunar iDXA, GE Healthcare) scans were performed before the start of preseason training for Men's Basketball, Baseball, Women's Volleyball, and Women's Soccer. End-season DXA scans were performed after the end of the regular season for Men's Basketball and Baseball athletes. Visceral Adipose Tissue was measured using CoreScan software provided by GE and Fat Mass Index (FMI) and Fat-Free Mass Index (FFMI) were calculated from scanned values.

Results: Between the various sports, there were several significant differences that were apparent. Height and percentage of Fat Mass (\%BF) were significantly different between all sports except Women's Volleyball and Women's Soccer. BMI, VAT, and FFMI were significantly different between males and females. Changes over a season showed increased BMD in Men's Basketball (2.79 to 2.99 Z-score, pre to end of season scan respectively; $\mathrm{p}<$ 0.001). No other observations were noticed to be significant. Conclusions: Sports-specific training and sex have large influences on the body composition of athletes. FMI and FFMI are two indices that may have a stronger indication to health than parameters considered for those who are sedentary and non-active. Female athletes have little to no amounts of VAT and this warrants further investigation.

Keywords: Body composition, DXA, Athlete 


\section{ACKNOWLEDGMENTS}

I would like to start by acknowledging my family for their support throughout my studies, and especially my mother, Rupa Dandekar, who's dedication to her children's futures has always been a priority. Thank you to my thesis advisor, Dr. Scott Reaves, for performing all of the scans required for this project. Thank you to the rest of my committee members: Dr. Kari Pilolla, for her support and guidance in my unique route of schooling, and Dr. Mary Oates. Lastly, thank you to my friends, colleagues, and mentors in the Food Science and Nutrition Department at California Polytechnic State University, for reminding me of the fun that comes with learning and the "learn by doing" method. 


\section{TABLE OF CONTENTS}

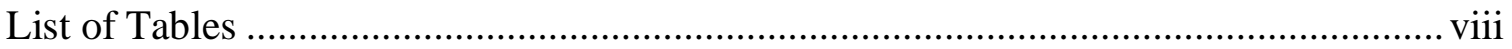

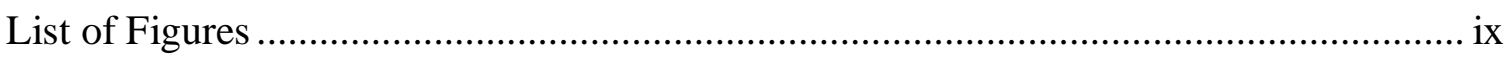

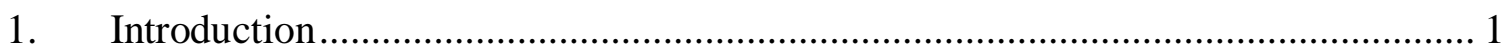

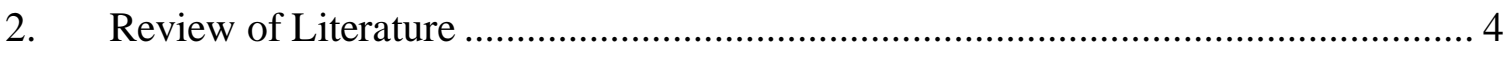

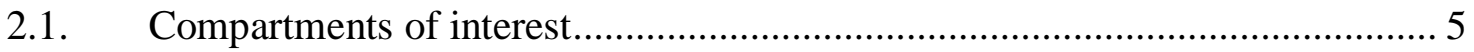

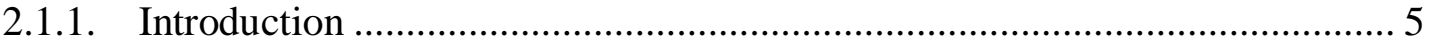

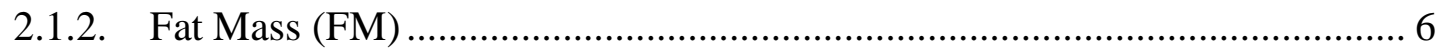

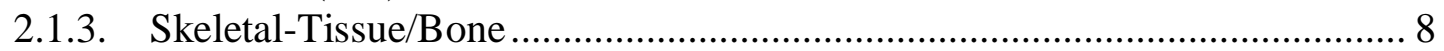

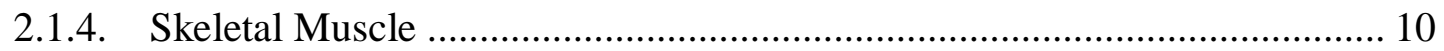

2.2. Normal Reference Values...................................................................... 11

2.2.1. Acceptable Normal Values .................................................................. 12

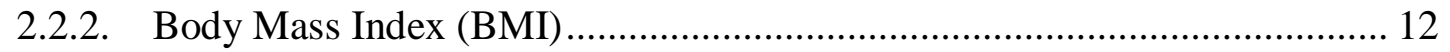

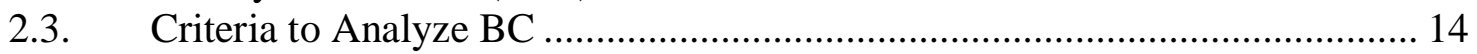

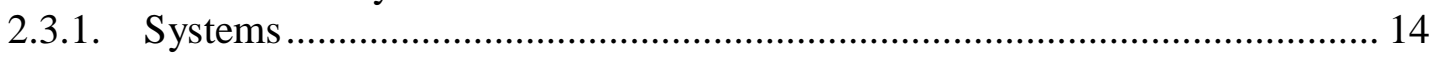

2.4. Methods of Assessing Body Composition.................................................... 15

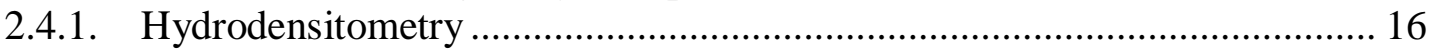

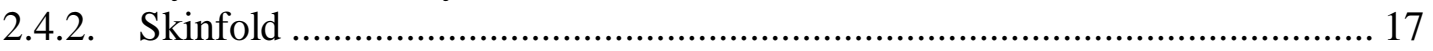

2.4.3. Air-Displacement Plethysmography ........................................................ 18

2.4.4. Bioelectrical Impedance Analysis ............................................................... 19

2.4.5. Dual-Energy X-ray Absorptiometry .......................................................... 20

2.4.6. Computed Topography (CT) and Magnetic Resonance Imaging (MRI) ..... 22

2.4.7. Conclusion on BC Methods.................................................................... 23

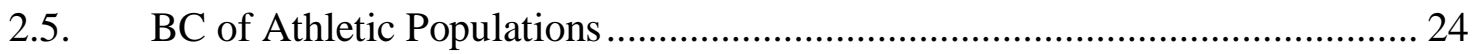

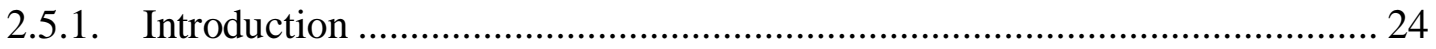

2.5.2. General Trends of Exercising Populations ................................................. 24

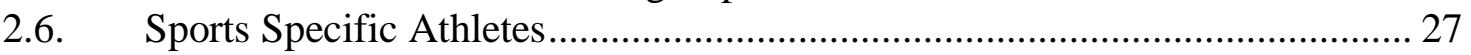

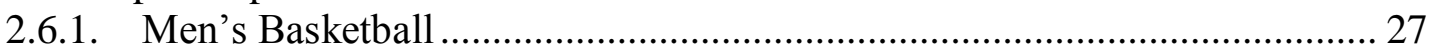

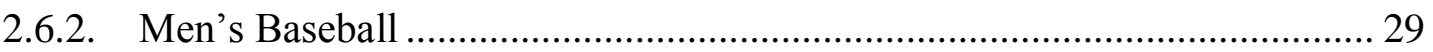

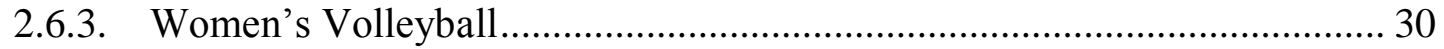

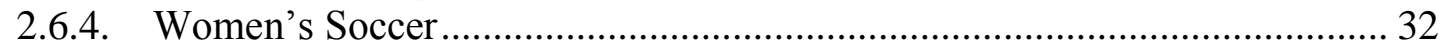

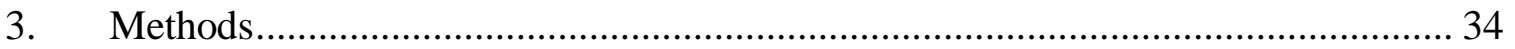

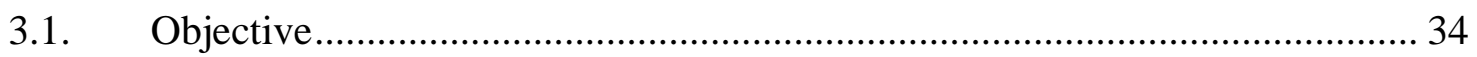

3.2. Assessment of Anthropometrics and Body composition (BC) ........................ 35

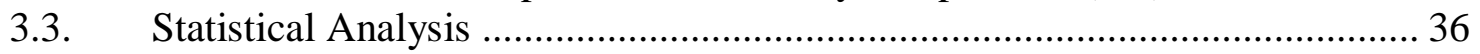

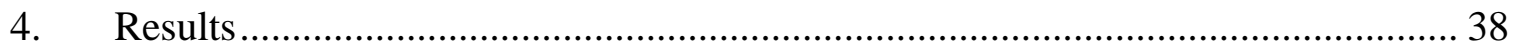

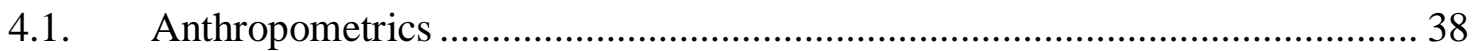

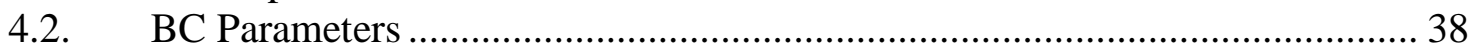

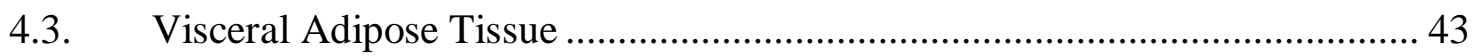

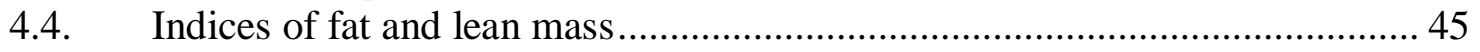


4.5. BC Changes in Men's Sports over a Competitive Season............................. 47

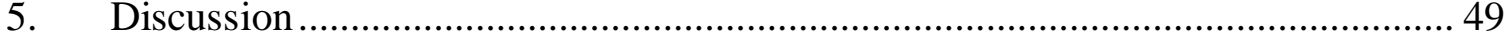

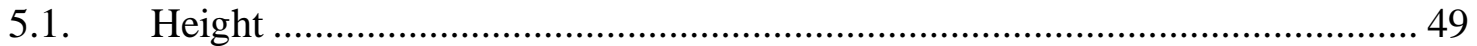

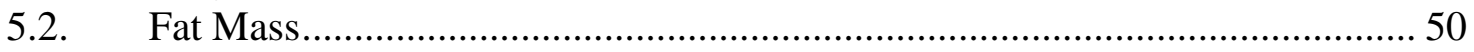

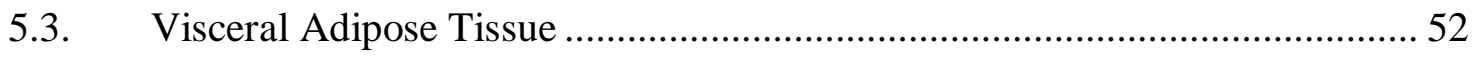

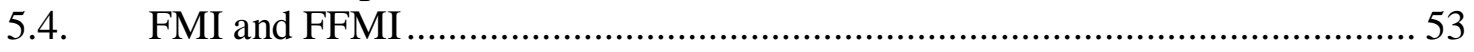

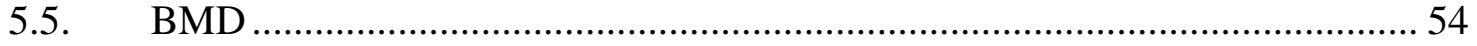

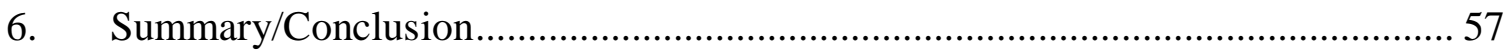

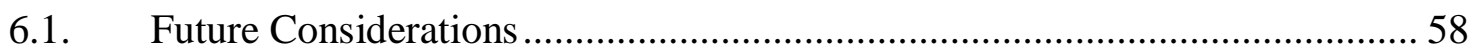

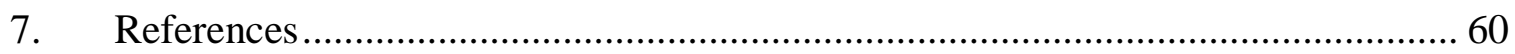




\section{LIST OF TABLES}

Page

Table 2.1 Body Fat Percentages for Standards of Health in Men and Women ............................. 8

Table 2.2 Bone Mineral Content of Various Populations ............................................................... 9

Table 2.3 Quetelet or Body Mass Index ............................................................................. 13

Table 2.4 Comparisons of Percentage of FM (\%BF) Between Athletes and Non-Athletes ......... 26

Table 2.5 Summary of BC Values for Men's Basketball ............................................................ 28

Table 2.6 Reference Values of Male Portuguese Basketball Players Using DXA ........................ 29

Table 2.7 Summary of Mean BC Values of BSB Student-Athletes ............................................. 30

Table 2.8 Summary of Mean BC Values for Women's Volleyball.................................................. 31

Table 2.9 Summary of Mean BC Values for Women's Soccer.................................................... 33

Table 4.1 Participant Anthropometrics ......................................................................................... 38

Table 4.2 Means of the Body Composition Measurements for the Various Sports ..................... 39

Table 4.3 Means of the Body Weight and Composition in MBB and BSB Before and After the

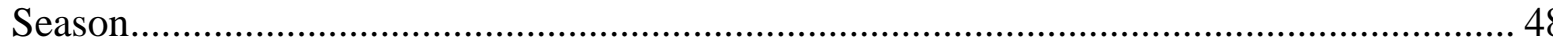




\section{LIST OF FIGURES}

Page

Figure 2.1 Compartments Within Each System Model. ........................................................ 15

Figure 2.2 Hydrodensity Equations ............................................................................. 17

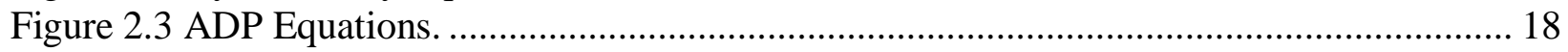

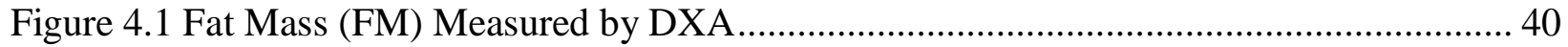

Figure 4.2 Percentage of Fat Mass (\%BF) Measured by DXA ............................................ 41

Figure 4.3 Amounts of Fat-Free Mass (FFM) in Pounds as Measured by DXA........................ 42

Figure 4.4 Distribution of Bone Mineral Density Measured by DXA. .................................... 43

Figure 4.5 Total VAT in Pounds as measured by DXA. ....................................................... 44

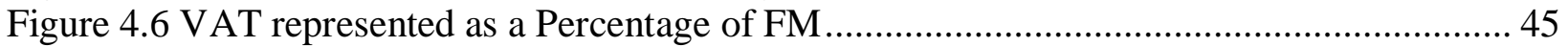

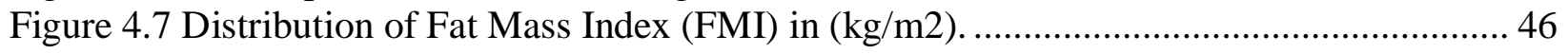

Figure 4.8 Distribution of Fat-Free Mass Index (FFMI) in Various Sports in (kg/m2)............ 47

Figure 4.9 Distribution of Bone Mineral Density in MBB and BSB Over a Season .................. 48 


\section{Introduction}

Body composition (BC) may estimate athletic performance. Training, nutrition, and overall health contribute to the restructuring of the human body to withstand the demands of athletic competition. Physiological adaptations result in the changes in the amount of muscle, bone, and fat on the body. The resulting appearance of an athlete stems from the demands of the sport and can indicate performance capacity. The study of $\mathrm{BC}$ has been widely used to assess the performance capacity of athletes (Bosch et al., 2014). Adverse changes in body weight or physiological structures can hinder performance, depending on the sport. With the recent trends in overweight individuals and the obesity epidemic in the US, the health of our athletes may be of concern (Ogden et al., 2006; Ogden, Carroll, Kit, \& Flegal, 2014).

$\mathrm{BC}$ is constantly discussed and scrutinized because of the effects on the performance and health of the athlete (Bosch et al., 2014). Studies on BC have been conducted to observe fat-free mass (FFM) and fat mass (FM), to understand baseline values and monitor changes from an intervention or over time (Ballard, Fafara, \& Vukovich, 2004; Bolonchuk, Lukaski, \& Siders, 1991; Bosch et al., 2014; Carbuhn, Fernandez, Bragg, Green, \& Crouse, 2010; Hoffman, Fry, Howard, Maresh, \& Kraemer, 1991; Hunter, Hilyer, \& Forster, 1993; Latin, Berg, \& Baechle, 1994; Penn et al., 1994; Santos et al., 2014; Stanforth, Crim, Stanforth, \& Stults-Kolehmainen, 2014). To date, studies continue to be conducted to examine BC of athletes and non-athletes at various ages.

Within BC assessments, there are different methodologies for measuring the different tissues that are of interest. From the 1950 s to the late 1990 s, densitometry was the most prevalent method and most frequently used method for measuring BC (Heymsfield, 2005; Heyward \& Wagner, 2004) having standardized the "whole-body density model” (Brožek, 
Grande, Anderson, \& Keys, 1963; Dupertuis, Pitts, Osserman, Welham, \& Behnke, 1951; Jackson \& Pollock, 1978; Mitchell, Hamilton, Steggerda, \& Bean, 1945). Today, with the improvements and advancements of technology, other methods have been developed that are: less stressful on the person being tested (e.g. BodPod), able to assess total body water (BIA and doubly labeled water), and provide more detailed measurements (Dual Energy X-ray Absorptiometry [DXA], Computed Tomography [CT], Magnetic Resonance Imaging [MRI]) (Heymsfield, 2005; Heyward \& Wagner, 2004). Before 2000, the hydrodensitometry method of measuring BC was considered the gold standard. Today, many consider DXA as the new gold standard at measuring BC (Heymsfield, 2005; Heyward \& Wagner, 2004). Thus, the objectives of this thesis are to use DXA technology on college-aged student athletes to determine:

I. Preseason differences in BC between Men's Basketball, baseball, women's volleyball, and women's soccer.

1. Hypothesis 1: DXA total body FM will differ between all sports examined for this study.

2. Hypothesis 2: DXA total body FFM will differ between all sports.

3. Hypothesis 3: DXA total body percentage of FM (\%BF) will differ between all sports

4. Hypothesis 4: DXA total body BMD will differ between all sports. 5. Hypothesis 5: DXA derived total weight of VAT will be lower in endurance-based sports.

6. Hypothesis 6: DXA derived total weight of VAT will be lower in studentathletes with lower total body $\% \mathrm{BF}$. 
II. Changes of BC over a course of a competitive season in men's basketball and baseball.

1. Hypothesis 1: DXA derived total body FM will be lower in end-season scans in MBB and BSB.

2. Hypothesis 2: DXA derived total body FFM will be lower in end-season scans in MBB and BSB.

3. Hypothesis 3: DXA derived total body BMD will not change over-theseason in MBB and BSB.

4. Hypothesis 4: VAT accumulation will be significantly higher in endseason and over-the-season in BSB than MBB.

Preseason DXA scans of NCAA Division-I Men's Baseball, Men's Basketball, Women's Volleyball, and Women's Soccer student-athletes were completed to observe the effects of various exercise-modes on BC outcomes (FFM, FM, Bone Mineral Density [BMD]; in absolute and relative terms). These measurements include visceral adipose tissue (VAT), which is a fat depot that is not well studied in athletes. Seasonal changes in BC was also observed for sport specific changes in $\mathrm{BC}$ between baseball and men's basketball. 


\section{Review of Literature}

Performance can be measured by tests and challenges that examine a human's mental, emotional, and physical abilities. A good example of testing physical performance is the Olympic games. This month-long tribute, to physical performance, tests and records the human's ability to perform better than previous years and generations. Occurring every four years, athletes train beyond what typical humans do every day, practicing nearly every day of the week, for multiple hours a day. Although some of these athletes have been training and practicing since their adolescences, physiological changes have allowed them to adapt to the training and become more efficient in their sport. Many of the physiological adaptations manifest as changes in phenotypic characteristics. These characteristics can be grossly described as body size, body shape, musculature, or amount of observable adiposity of the body. Studying these characteristics can be useful in understanding how the training influences the body or if the athlete is healthy and progressing through training. Investigating the $\mathrm{BC}$ of an amateur can help compare his/her performance outcomes to the body type of a successful professional athlete.

The study of $\mathrm{BC}$ encompasses the observation of phenotypic characteristics. $\mathrm{BC}$ can also be used to observe the body's restructuring and retention of nutrients from the environment (Heymsfield, 2005). Measuring BC must follow the simple rule of: all measurements must sum to the whole. In other words, the body weight (the whole) must equal the sum of all the organs and organ systems. Today, measuring organ size is possible, yet investigators in the past did not have the technology or resources to be able to measure organs without harming the subject. Indirect measuring was devised to work around this problem. For example, measuring waist circumference was often a method used to estimate the total amount of fat on the body. When studying the $\mathrm{BC}$ of athletes in relation to performance, it may be more difficult to measure some 
parts, or compartments, of the body by using circumferences alone. Compartments such as bone mineral, certain fat depots, and musculature, which all have a strong influence on athletic performance, is better assessed through today's technology. By repeating measurements on an athlete over time, physiological adaptations can be observed; initial measurement of $\mathrm{BC}$ of athletes can reveal how prepared their body is to the sport/physical activity, and whether additional training is required.

In the fields of exercise physiology, nutrition, and applied physiology (and their associated sub-specialties), studying BC can track progress and help understand changes in the body's ability to adapt to stressors. Primary outcomes that have been observed are fat mass (FM) and fat-free mass (FFM). With the advancement in technology, the availability of certain methods to measure $\mathrm{BC}$ has allowed observation of bone mineral. These three compartments have been known to readily change due to modifications in nutrition, training, and lifestyle modifications. The following literature review will explore the compartments of interest and methods for measuring BC. This review will also highlight the gaps in the literature and will address topics that must be further investigated.

\subsection{Compartments of interest}

\subsubsection{INTRODUCTION}

The first whole-body compositional analysis at the molecular level (discussed later) was reported by Mitchell et al. (1945) (as cited from Heymsfield et. al., 2005). This early in vivo method was only capable of estimating different compartments with underlying assumption that certain molecules had uniform weight (Heymsfield, 2005). Current popular BC methods commonly measure changes in three major tissue types: fat, bone, and non-fat tissue, to quantify 
adipose tissue, skeletal tissue, and skeletal muscle tissue, respectively, and better understand their interrelationship with health and performance.

\subsubsection{FAT MASS (FM)}

The compartment of fat mass (FM) encompasses the tissue system of adipose tissue (AT), an endocrine organ (Sherwood, 2015). AT is comprised of various cell types to aid in the hormonal regulation of appetite, thermoregulation, insulation, and storage of energy (Abraham, Pedley, Massaro, Hoffmann, \& Fox, 2015; Ibrahim, 2010). AT is made of adipocytes, other nonfat cells, connective tissue matrix, vascular tissues, neural tissues, fibroblasts, preadipocytes, immune cells, and inflammatory cells (Ibrahim, 2010). Adipocytes are the main cell type that make up AT and their primary function is to store energy as triglycerides (Ibrahim, 2010). Adipocytes are cells to store fats and lipid molecules in the post-prandial state, while they are still highly vascularized and accessible (Ibrahim, 2010). Once these adipocytes retain a certain amount of triglycerides, they exceed the normal physiological size and become dysfunctional (Ibrahim, 2010). Large adipocytes lose their ability to release triglycerides and do not respond to hormonal cues (Ibrahim, 2010). Depending on their location, these adipocytes can cause harm over time.

Adipocyte location varies on the amount of triglycerides stored in the body. For BC assessment, two types of FM are considered, the subcutaneous adipose tissue (SCAT) and visceral adipose tissue (VAT). SCAT is the depot of adipocytes that lies directly beneath the skin, across the entire body (Ibrahim, 2010). Depending on sex and genetic factors, certain regions of the body will have more SCAT than others; men tend have more on their abdomen, back, and arms, while women tend to have more in the gluteal and thigh regions and more 
overall distribution. When these depots become saturated or overall body FM reaches a threshold, FM begins to accumulate in the abdominal cavity covering the mesentery, omentum, and viscera (Ibrahim, 2010). This accumulation of FM in the abdominal cavity is called VAT. Seminal studies have found that SCAT and VAT vary between sex, race, and ethnicity (Bidulescu et al., 2013; Blaak, 2001). Additionally, the amount of VAT in an individual can be predicted based on the amount of SCAT since it correlates with the amount of VAT (Bosch et al., 2015a). Observations show that men have proportionally higher VAT than women (Heymsfield et. al.,Bosch, Dengel, Ryder, Kelly, \& Chow, 2015b; 2005; Miazgowski et al., 2017). Sexual dimorphisms of VAT accumulation begin during puberty and increase over time with age (Enzi et al., 1986). The patterns in VAT amounts are similar to patterns in cardiovascular risk between genders (Bosch et al., 2015a).

While these depots vary in amounts, the accumulation of FM is highly dependent on the fitness level and energy expenditure of the individual. The excessive accumulation of fat from reduced physical activity, sedentary lifestyle, excess energy intake, or hormonal dysregulation can result in obesity. Obesity is diagnosed when an individual's body mass index (BMI) is greater than or equal to $30 \mathrm{~kg} / \mathrm{m}^{2}$, this is the weight divided by the square of the height (more details provided in Section 2.2.2.). The opposite trend, where accumulation of FM is very low, can be due to a highly active lifestyle, high physical activity, low energy intake, or hormonal dysregulation. Athletic populations tend to have lower FM than non-athletic individuals (Sonksen, 2016). Table 2.1 tabulates the differences and recommended ranges of FM for various populations as a percentage of total body weight (Lohman, Houtkooper, \& Going, 1997). There are various methods for measuring FM which will be discussed in later sections and this table (Table 2.1) includes values from various methods of analysis. 
Table 2.1 Body Fat Percentages for Standards of Health in Men and Women

\begin{tabular}{lccc}
\hline & LOW & MID & UPPER \\
\hline Men - Non-active & 8 & 13 & \\
Young adult & 10 & 18 & 22 \\
Middle Age & 10 & 16 & 23 \\
Elderly & & & \\
Men-Active & 5 & 10 & 15 \\
Young Adult & 7 & 11 & 18 \\
Middle Age & 9 & 12 & 18 \\
Elderly & & & \\
Women - Non-Active & 20 & 28 & 35 \\
Young Adult & 25 & 32 & 38 \\
Middle Age & 25 & 30 & 35 \\
Elderly & & & \\
Women - Active & 16 & 23 & 28 \\
Young Adult & 20 & 27 & 33 \\
Middle Age & 20 & 27 & 33 \\
Elderly & & & \\
\hline
\end{tabular}

Adapted from (Lohman et al., 1997)

\subsubsection{SKELETAL-TISSUE/BONE}

The compartment of bone mineral content/density (BMC/D) is skeletal tissue, or bone, which is the organ system that gives the body its structure. The primary functions of the skeletal system include the transmission of forces from one part of the body to another, protection of vital organs, storage of minerals, some endocrine functions, and hematopoiesis (Martin, 2015). Bone can be divided into two subtypes of histological appearance and structure: cortical and cancellous bone. The former being the type that makes the long shafts and the latter being the porous structure seen at joints and in cuboidal bones. The molecular components of bone by weight are $70 \%$ mineral (crystalline apatite of calcium phosphate; and hydroxyapatite of strontium, lead, carbonate, and fluoride), $20 \%$ organic matrix (90\% collagen, specifically Type I, III, and IV collagen, and 10\% non-collagen species like chondroitin), 5\% water, and 5\% fats 
(Martin, 2015). Increasing the mineral amount can create stiffer bones that are more resistant to fracture and injury.

The mass of total BMC is highly dependent on sex, ethnicity, nutritional intake, and fitness level. As discussed by Heymsfield (2005), a dry-defatted skeleton weighs 4.0 and $2.8 \mathrm{~kg}$ for a young male and female, respectively, which corresponds to 6-7\% of the total body weight. Bone mineral composes $4-5 \%$ of the body mass in adults. As seen in Table 2.2, Trotter and Hixon (1974) have reported BMC between different American races and genders. Currently, only a few ethnicities, races, and populations have averages/standards in bone mineral measurements established for their respective groups.

Table 2.2 Bone Mineral Content of Various Populations

\section{Population Bone Mineral Content}

\begin{tabular}{lc} 
Black male & $3899 \mathrm{~g}$ \\
White male & $3446 \mathrm{~g}$ \\
Black female & $2846 \mathrm{~g}$ \\
White female & $2335 \mathrm{~g}$ \\
\hline
\end{tabular}

The table demonstrates that bone mineral content in males is significantly higher than females and that race is a factor in basal content. This information was adapted from Trotter and Hixon (1974).

Changes in bone mineral occurs during the growth of an individual. The majority of mineral deposition and calcium absorption occurs during the pubertal phase but increases and peaks in the late 20 s to early 30 s. For BC measurement, quantifying bone tissue, in vivo, was previously difficult to accomplish until technological advances streamlined the process making it more feasible (Heymsfield, 2005). Past studies that used bone sections and radiographs have elucidated variability in BMC and BMD with age, sex, ethnicity/race, and physical fitness levels 
(Heymsfield, 2005; Malina, 2007). The loss of bone can cause frailty, as seen in those individuals with osteopenia or osteoporosis. These disease states are the significant and extreme loss of bone mineral that makes the bone more porous and prone to fractures. Identifying osteoporosis was not feasible prior to the late 1980s due to the lack of the necessary equipment and technology. In 1988, the FDA approved the dual energy x-ray absorptiometry (DXA) for the diagnosis of osteoporosis and measurement of bone mineral. Advancements in technologies, such as DXA and dual photon absorptiometry (DPA), have helped make studies on BMC and BMD measurement easier to complete (Heymsfield, 2005).

\subsubsection{SKELETAL MUSCLE}

Skeletal muscle is part of the musculoskeletal system of the human body. It comprises greater than $45 \%$ of body weight. All skeletal muscles are striated muscle, meaning that the organization of the cells of the muscle are visible to the naked eye as observed striations. The functional component of the muscle is called the sarcomere, in which cross-linked proteins pull across each other to generate force. The molecular components of skeletal muscle are $75 \%$ water, $20 \%$ proteins, and $5 \%$ other minerals, fats, carbohydrates, and inorganic salts (Frontera \& Ochala, 2015). Skeletal muscle allows movement, stabilizes body positions, moves fluids throughout the body (lymph, blood, and chyme), and regulates body heat (Sherwood, 2015).

Without training, natural musculature varies between race, ethnicity, and sex. In general, men have higher muscle mass than women, athletes have more than non-athletes, and active individuals have more than sedentary individuals. But there is currently no recommended range of musculature because it is highly dependent on the needs of the individual. High musculature is associated with greater strength, increased resting energy expenditure (REE), higher insulin 
sensitivity, stronger cardiovascular and pulmonary systems, etc. (Frontera \& Ochala, 2015; Lee, Hsieh, \& Paffenbarger, 1995; Paffenbarger Jr, Hyde, Wing, \& Hsieh, 1986). For BC, measuring skeletal muscle was limited in the past because it was difficult to extrapolate skeletal muscle values with old technologies. With the advents of X-ray and magnetic resonance imaging methods, skeletal muscle measurements are more feasible (Heymsfield, Adamek, Gonzalez, Jia, \& Thomas, 2014; Kim et al., 2004; Kim, Wang, Heymsfield, Baumgartner, \& Gallagher, 2002). Previous methods estimated skeletal muscle amounts based on fat-free mass (FFM) (which included bone mass as well) when densitometry and other methods measured for FM and FFM.

For the purposes of this study, FFM is considered primarily skeletal muscle and bone, however it is important to note that FFM is actually a all of tissues and organ systems except FM.

\subsection{Normal Reference Values}

Over the last 30 years, the US has seen a $23 \%$ increase in overweight and obese individuals (Ogden et al., 2014). This increase in the prevalence of overweight and obese individuals has led to a change in the 'average' body size to a larger body size. Epidemiological studies primarily use methods of whole-body measurements (described in Section 2.2.2). Normal values have been established from various seminal studies and reference bodies, which have been used to estimate body weight distribution.

Over the last few decades, there have been improvements in the technology to accurately measure and distinguish the composition of elements, molecules, tissues, organs, and organ systems in the body. These new technologies range in precision, cost, invasiveness, and availability. Section 2.4 will provide details about different BC methods in the tissue-system and whole-body models. 


\subsubsection{ACCEPTABLE NORMAL VALUES}

In the following sections, values for "healthy BC" will be provided for each method, as different methods use different scales. Regardless of the method, the compartment that is being measured usually has a universal scale that can be referenced. With increased attention to body adiposity, or amount of FM on the body, studies have indirectly derived a range of what is considered healthy body adiposity. Percentage of FM to body weight (\%BF) can be used synonymously with body adiposity and an article by Lohman et al. (1997) has re-identified this range for young men's BF\% which is between 8 and $22 \%$ and for young women's is $20-35 \%$ for healthy non-athletic adults (see Table 2.1). \%BF, or the relative amount of adipose tissue, can be dependent on various factors although in most cases it is due to excessive energy intake.

Skeletal tissue, or bone, is another tissue system that can be measured. Studies have identified total mineral content differences that may be due to differences in sex and race (see Table 2.2) (Trotter \& Hixon, 1974). The remaining tissues of skeletal muscle, organs, hair, body water, etc. are all highly variable and that is the reason why studies are measuring these outcomes. When referencing fat-free mass, also known as lean body mass, we are including bone and all the tissues other than fat that can be measured.

\subsubsection{BODY MASS INDEX (BMI)}

Due to the rising obesity epidemic, researchers and health professionals have increased the use of body mass index (BMI) as a simple and effective tool for whole body measurement in human populations (Wang, Heshka, Pierson, \& Heymsfield, 1995; Wang, Ma, Pierson, \& Heymsfield, 1993; Wang, Pierson, \& Heymsfield, 1992). However, this has proven to be less useful in more recent years; the distribution of fat mass (FM) and fat-free mass (FFM) has 
revealed the inaccuracies of using BMI as a measurement of health among active populations. Though BMI can potentially classify individuals with inaccurate measures of health, they continue to be widely used to this day.

The Quetelet Index was developed in 1835, based upon Adolphe Quetelet's study on human population that "weight increases nearly as the square of the height" within a normally distributed population (Eknoyan, 2008). The practical use of Quetelet findings changed into the currently used phrase of BMI (coined by Ancel Keys in the $20^{\text {th }}$ century), which was used by insurance agencies to calculate mortality risk to establish insurance premiums (Eknoyan, 2008). Since its debut, the use of BMI has been widely used to determine health and relative risk of morbidity and mortality. Table 2.3 provides detailed values of the "Quetelet Index and BMI classifications."

Table 2.3 Quetelet or Body Mass Index

\begin{tabular}{c|l} 
Value $(\mathrm{kg} / \mathrm{m} 2)$ & Classification \\
\hline$<18.5$ & Underweight \\
$18.5-24.9$ & Normal \\
$25.0-29.9$ & Overweight \\
$30.0-34.9$ & Obese: Class 1 \\
$35.0-40.0$ & Obese: Class 2 \\
$>40.0$ & Morbidly Obese
\end{tabular}

The various classifications of BMI were designated by the National Institute of Health in June 1998. These guidelines changed the classifications of overweight and obese to what they are today. Table is adapted from (National Heart \& Institute, 1998).

While this table is able to describe the ratio of mass to height and its possible disproportionality, it does not discriminate between fat- and muscle-tissue mass among individuals. More recent research also shows that being overweight potentially has a lower relative risk for mortality (Flegal, Kit, Orpana, \& Graubard, 2013; Kopelman, 2007; Lee, Blair, 
\& Jackson, 1999; National Heart \& Institute, 1998) and improved outcomes in certain disease states (e.g. chronic kidney disease).

Assessment using only height and weight is an efficient way to evaluate a person's health status without using methods that may be expensive, time-consuming, or invasive. However, the sensitivity and reliability of using BMI changes between populations (i.e. ethnicities and fitness level) and may lead to error and inaccurate classification of an individual's level of health risk. More effective methods have been developed not only to explore populations but to understand the changes in $\mathrm{BC}$ due to variation between individuals.

\subsection{Criteria to Analyze BC}

Starting in the early 1900s, BC measurement was used when analyzing various organ weights in fetuses and infants (Ellis, 2000). It was during the 1950s - 1970s that cadaver analyses of adults were performed to understand BC (Ellis, 2000). Since then, chemical and molecular analyses of whole bodies have been conducted as well. It has been noted that the “chemical composition of the body's various tissues is relatively constant among individuals, although not constant from birth," (Ellis, 2000).

\subsubsection{SYSTEMS}

Wang et al. (1993) summarizes how the analysis of BC can be performed through five system models of analysis: 1) atomic, 2) molecular, 3) cellular, 4) tissues/functional, and 5) whole body. In some of these systems, it is easier to measure within a single system model than across multiple systems. For instance, the atomic system model can be measured by using potassium-40 counting or delayed gamma neutron activation techniques, which will measure the elements present in the body (Wang et al., 1992). In current studies, there is an overlap of 
different systems to identify $\mathrm{BC}$ as the particular outcomes are related to morbidity or evidence of adaptation. Figure 2.1 shows the different outcomes that each system can exhibit and the outcomes that researchers are interested in observing.

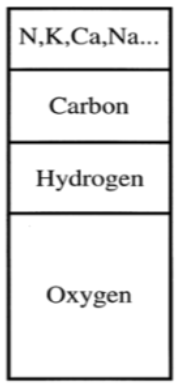

Atomic

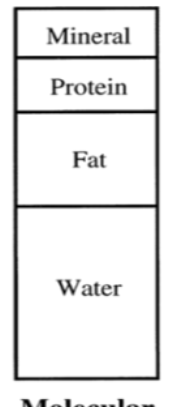

Molecular

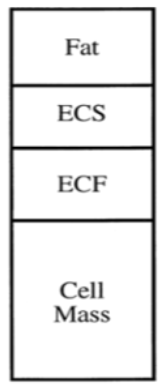

Cellular

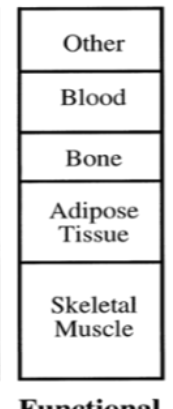

Functional

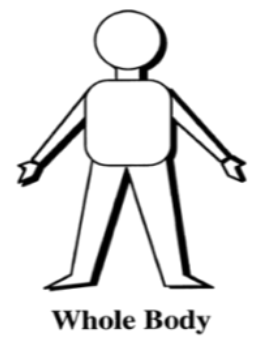

\section{Figure 2.1 Compartments Within Each System Model.}

This image depicts the various compartments that can be measured in the different systems. ECS, Extracellular solids; ECF, Extracellular fluids. Taken from Ellis (2000).

\subsection{Methods of Assessing Body Composition}

In a body composition lecture by the International Society for Clinical Densitometry (ISCD), known methods were scrutinized based on their approach to measuring outcomes, this was organized based on how the method had referenced and validated their results (ISCD, 2017; Martin \& Drinkwater, 1991b). Level 1 validation is a direct measurement of the tissue without the use of an assumption(s) (e.g. dissection) (Martin \& Drinkwater, 1991a). An assumption: is the use of a value or known amount of an outcome to help calculate or measure the other outcomes of interest. Level 2 validation is a direct or indirect measurement of the tissues with one or more assumptions of tissues (Martin \& Drinkwater, 1991a). Level 3 validation is a double indirect measurement that uses a level 2 validated method as a validation method (Martin \& Drinkwater, 1991a). Recognizing that not all methods are equal, selecting a specific method requires an understanding of the variables being studied. 


\subsubsection{HYDRODENSITOMETRY}

During the 1950's, researchers shifted their focus to understanding the BC of men in order to appropriately classify them into different body shapes and sizes. One approach was to measure the specific gravity of the body by submerging the entire body in a tank of water (Dupertuis et al., 1951). This was one of the first studies to use underwater weighing (UWW) (also called hydrodensitometry, HD) to measure body density, which is the basis of calculating FM and FFM. From the 1960s to 2000s, UWW has been the "gold standard" for measuring BC(Ellis, 2000; Heymsfield et al., 2015; Pietrobelli, Heymsfield, Wang, \& Gallagher, 2001). UWW/HD is a 2-Compartment model (2C), as it first measures body density, a whole body system compartment, and then inputs this value into a formula which provides information on the true compartments of FM and FFM for a certain population (see Figure 2.2) (Ellis, 2000). This method is considered a Level-2 validated method for it uses assumptions on the densities of FM and FFM (Martin \& Drinkwater, 1991a) The consistency in use of this method has led to a variety of regression equations for different populations (Heyward \& Wagner 2004) as well as the obvious criticism of "the validity of a constant density for the compartment of FFM" (Ellis, 2000). FFM may be dependent on a variety of factors such as gender and ethnicity (Cote \& Adams, 1993), age, disease state, or physical activity level (Heymsfield et. al.,1993). This is because FFM is made up of water, protein, minerals, and fats and has been observed to change due to these factors previously mentioned. 


$$
\begin{gathered}
D_{b}=\frac{M_{b}}{V_{b}} \\
V_{b}=\left(W_{a}-W_{w}\right) / D_{w}
\end{gathered}
$$

\section{Figure 2.2 Hydrodensity Equations}

These equations represent the mathematical process to calculate body density (Db) to then calculate FM and FFM. The bottom formula is simplified equation to calculate body volume from hydrodensity measurements. $\mathrm{Mb}=$ Body Mass. $\mathrm{Vb}=$ Body Volume. $\mathrm{Wa}=$ Body Weight in air. $\mathrm{Ww}=$ Body Weight in water. $\mathrm{Dw}=$ Density of water at specific temperature.

\subsubsection{SKINFOLD}

Skinfold measurement (SKF) is a 2C-model for assessing FM and FFM by measuring the SCAT via skin thickness. The use of this method was popularized in the late 1970s after the Jackson-Pollock equation was created (Jackson \& Pollock, 1978). These original equations were based off of a 2C Siri model that was used often in hydrodensitometry measurements (Jackson \& Pollock, 1978; Jackson \& Pollock, 1984, 1985).

This method is considered a Level-3 validation, as it validates its measurements on a method that already has assumptions (UWW, HD, DXA). In 2009, Jackson et. al. recalculated variables in their equations to fit the population for present day Americans to account for different ethnicities and races. This study also utilized dual energy X-ray absorptiometry for validation instead of hydrodensitometry to address use of the new gold standard in body composition. Skinfold measurements can be quick, relatively painless, non-invasive, and low in cost to use. Inaccuracies with this method are from: mastery/experience of the technician using the calipers, hydration status of the individual being measured, and differences in ethnicity, race, and fitness status of the individual. While this method is useful for low cost and quick assessments, SKF is not appropriate when precision and objective measurement is necessary. 


\subsubsection{AIR-DISPLACEMENT PLETHYSMOGRAPHY}

Air Displacement Plethysmography (ADP) is conceptually similar to UWW in that it is a 2C model and measures body density via measuring body volume (Heyward \& Wagner,2014). The difference is the method to measure body volume. ADP uses air instead of water as the medium for measurement. Therefore, it is not using Archimedes' buoyancy principle but instead uses Boyle's law as its underlying principle (Heymsfield et. al., 2005; Heyward \& Wagner, 2004). The energy system within the chambers is kept at a constant temperature with no transfer of heat (adiabatic), thus Poisson's Law is used instead (Figure 2.3) (Heyward \& Wagner, 2004).

$$
\begin{gathered}
\frac{P_{1}}{P_{2}}=\frac{V_{2}}{V_{1}} \\
\frac{P_{1}}{P_{2}}=\left(\frac{V_{2}}{V_{1}}\right)^{\gamma}
\end{gathered}
$$

\section{Figure 2.3 ADP Equations.}

The top equation is Boyle's Law. This is when we are in isothermal conditions. The bottom equation is Poisson's Law. This is equation used under adiabatic conditions. $\mathrm{P}_{1}, \mathrm{~V}_{1}=$ one paired condition. $\mathrm{P}_{2}, \mathrm{~V}_{2}=$ second paired condition. $=$ ratio of the specific heat of the gas at constant pressure to the constant volume.

ADP uses an egg-shaped chambered device that has two chambers of known volume. A person will be in skin-tight/conforming apparel and sit in the large chamber, thus displacing a volume of air. An oscillating diaphragm will change the pressures between the two chambers to calculate the displaced volume (Heysmfield et. al., 2005). Similar to UWW, this methodology does not consider the ethnicities, fitness status, or amount of hair on the body of the subject, which can change the measurement of underlying assumptions used in this method. Unlike UWW, the participant will not have to uncomfortably expel air while underwater but may be subject to claustrophobic space. This method uses assumptions for the densities of tissues and is 
similar to UWW, this BC method is given a Level-2 validation as mentioned by ISCD. It should be noted that the stand-alone measurement of FM and FFM by the ADP system can have inaccuracies due to the equations used once whole body density is measured (i.e. Siri $2 \mathrm{C}$ for whites and Schutte 2C for blacks).

An observed difference of $-4.0 \%$ to $1.9 \% \% \mathrm{BF}$ is seen when ADP is compared to UWW. When ADP is compared to the four-compartment (4C) model - which includes DXA - there is an over estimation of \%BF by 1.8 to $2.8 \%$ (Heymsfield, 2005; Heyward \& Wagner, 2004). However more recent evidence has shown improvement in accuracy when compared with DXA alone (Ballard et al., 2004). When ADP is combined with DXA in a 4C model, it further improves the accuracy of FM measurement (Heyward \& Wagner, 2004).

\subsubsection{BIOELECTRICAL IMPEDANCE ANALYSIS}

Bioelectrical Impedance Analysis (BIA) is completed by sending an electrical current through the body and analyzing the impedance (Heyward \& Wagner, 2004; Moon, 2013; Zemel \& Barden, 2004). By measuring the impedance, it is also possible to estimate the total body water due to the electrolytes present in the water content of the body. By utilizing this information, it is possible to estimate FM and FFM as the resistance in FFM is less due to the higher water content when compared to the FM's low water content (a poor conductor of electricity) (Heymsfield et. al., 2005; Heyward \& Gibson, 2014; Heyward \& Wagner, 2004; Malina, 2007). The underlying assumptions that make this method work are that FFM is made up of $\sim 73 \%$ water, the measure of resistance and impedance is based on the figurative idea that the human body is made up of cylinders (Heymsfield et. al., Ellis, 2000; 2005; Lee \& Gallagher, 2008; Moon, 2013). Thus measuring the resistance, reactance, and impedance based on the 
single or multifrequency electrical currents can give total body water (TBW) or FFM based on previously determined equations (Ellis, 2000). Although this method has been useful as a noninvasive tool, it can be expensive depending on the manufacturer and the functions of the machine.

This method is considered a level 3 validation as it is validated by HD or DXA. Hydration status can change the estimate of FFM significantly and can be seen by the margin of error of $\pm 3.5 \mathrm{~kg}$ and $\pm 2.8 \mathrm{~kg}$ FFM in men and women, respectively (Heyward \& Wagner, 2004). Additional margins of error have been noted in various measurements: $0.9-1.8 \mathrm{~kg}$ TBW, 2.0 $3.0 \mathrm{~kg}$ in FFM, and 3.0 - 4.0\% FM (Houtkooper, Lohman, Going, \& Howell, 1996).

\subsubsection{DUAL-ENERGY X-RAY ABSORPTIOMETRY}

Dual Energy X-ray Absorptiometry (D(E)XA) is a form of BC analysis which uses the attenuation of X-rays at low and high photon energies (Ellis, 2000; Heymsfield et. al., 2005; Heyward \& Wagner, 2004). By using two different levels of photon energies, the X-rays can pass through the individual and identify the various tissue compositions, differentiating between FM, lean soft tissue mass (LST), and bone mineral mass (Ellis, 2000; Heyward \& Wagner, 2004;

Lee \& Gallegher, 2008; Lohman \& Chen, 2005). DXA can directly measure bone mass and has a procedure that is more comfortable for the client being measured in comparison with the procedure used in UWW (Heymsfield et. al., 2005). This device measures different tissues, although it assumes the densities from a reference value, thus making this a $3 \mathrm{C}$ model with a level 2 validation. It also allows for variances between individuals as it directly measures bone mass. 
As the X-rays from the machine are emitted, they pass through the body and are detected by a collector on the opposite side of the emitter (Heymsfield, 2005). The crystal inside the collector measures the change in the energy after passing through the different body tissues (Prado \& Heymsfield, 2014). The changes are translated to electrical currents which are amplified and transfigured by the manufacture's computer to the visible output (Healthcare, 2017). Therefore, calculations for photon changes are based on the photoelectric effect and Compton scattering (Ellis, 2000; ISCD2017).

Compared with the other two Level 2 Validation methods, UWW and ADP, which require an additional step of calculating FFM from body density, DXA offers the best direct measurements of FM and FFM (Heymsfield et. al.,2005; Heyward \& Wagner, 2004). The accuracy of DXA to identify adipose tissue is unparalleled by lower cost methods; however, the exposure to harmful X-rays can be a deterrent to participants. While precautionary measures must be taken with any radiation exposure, the actual X-ray exposure of DXA ranges from 0.2 to 0.8 mrems, which is comparatively lower than 4 - 6 mrem as experienced when flying from Los Angeles to New York City (Healthcare, 2017; Heymsfield, 2005). The radiation may also be harmful to an unborn fetus, therefore there is a requirement that women of childbearing age take a pregnancy test before being measured.

Despite these potential deterrents, DXA scans have the added benefit of being able to capture whole body composition while having the ability to focus on selected body segments. This effectively allows for individualization of the measurement by accounting for differences in ethnicity/race, fitness level, and current health status (Ellis, 2000; Heyward \& Wagner,2004; Lee \& Gallagher, 2008; Lohman \& Chen, 2005). When comparing to common Level-3 validation methods like BIA and SKF, DXA provides direct body composition measurements; and today, 
DXA has been used to validate these indirect methods (Ellis, 2000; Heymsfield et al., 2015). An additional consideration for researchers is the expensive purchasing price and storage space required for the large DXA device. Unlike DXA, the strengths of other BC methods include ease of use, lower cost, user familiarity, and no requirement for specialized training and state licensing to perform testing.

A further limitation of using DXA scans is decreased accuracy compared to level 1 validation methods, like CT and MRI, which can also distinguish more tissues types (ISCD, 2017). Furthermore, DXA cannot measure molecular level accuracy of fat in certain tissues (i.e. inter- and intra-muscular values).

\subsubsection{COMPUTED TOPOGRAPHY (CT) AND MAGNETIC RESONANCE IMAGING} $(\mathrm{MRI})$

Both Computed Tomography (CT) and Magnetic Resonance Imaging (MRI) are multicomponent models that use direct measurements of all types of tissues and differentiate tissues and organs. CT uses X-rays to scan the body and create horizontal slices that create a threedimensional map of the "trunk and peripheral muscle area and volume, muscle attenuation, [and] deep and superficial subcutaneous adipose tissue separated only by a thin fascia," (ISCD, 2017; Oates, 2017). CT is not only very useful in body composition measurements, but also can identify other disease states. Limitations of conducting CT scans includes the increase in radiation $(270 \mathrm{mrem})$ in comparison to DXA $(0.2-0.8 \mathrm{mrem})$ and the high costs of operation (Heymsfield, 2005). MRI uses proton imaging by creating a magnetic field around the individual to align the protons and capture it on imaging software (Ellis, 2000; Heymsfield et. al., 2005; Lee \& Gallagher, 2008; Zemel \& Barden, 2004). Due to the strong magnetic field 
created, MRI's cannot be performed on individuals with implanted metal pieces and may also cause headaches. Certain tissue types can be observed with high acuity, while others require different imaging techniques as the content of water in these tissues varies and may not be accurately observed (Heymsfield et. al., 2005; Lee \& Gallagher, 2008). These limitations could be because of the budget of the hospital or practice. Certain dyes may also be required, but not necessary for body compositional testing. Like the CT, costly MRI procedures can distinguish subcutaneous, visceral, organ, and intermuscular fats while also being able to measure water and lipid amounts(Ellis, 2000; Lee \& Gallagher, 2008). This high resolution of magnetic resonance can also distinguish between muscle fiber bundles (Heymsfield et al., 2014). Accuracy of these methods has been evaluated by biopsy studies and has high reliability (Heymsfield et. al., 2005). While the precision of these instruments is highly useful in creating accurate measurements, these instruments are costly to buy and run, and are not easy to move when changing locations.

\subsubsection{CONCLUSION ON BC METHODS}

To summarize, there are various modalities and methods available for measuring BC. The overall cost of each modality increases exponentially with the number of compartments visualized and the accuracy of the machine. These parameters along with which $\mathrm{BC}$ compartment is to be measure will determine which method will be best suited. Researchers must consider the feasibility and accuracy of their study by assessing the method of measuring $\mathrm{BC}$ and its ability to measure various types of tissue compartments and must understand that variability in exercise-exposure, ethnicity, race, and other demographic factors of participants may impact results. 


\subsection{BC of Athletic Populations}

\subsubsection{INTRODUCTION}

Exercise is defined as "a type of physical activity consisting of planned, structured, and repetitive bodily movement done to improve and/or maintain one or more components of physical fitness" (Caspersen, Powell, \& Christenson, 1985). Individuals who participate in exercise will often find that their body adapts with grossly observable phenotypic responses and physiological changes that can be observed with various other technologies. The BC of athletes, or those who exercise regularly, must be able to withstand the forces of exercise and retain adequate energy to sustain exercise.

An athlete is one who is trained or skilled in exercise, sport, or game requiring physical strength, agility, and stamina (Merriam-Webster, 2018). An athlete can participate in a team sport such as soccer, basketball, baseball, or volleyball. The following sections will describe the $\mathrm{BC}$ and its importance in the athletic population.

\subsubsection{GENERAL TRENDS OF EXERCISING POPULATIONS}

Exercise and physical activity influence metabolism and lower the risk of mortality (Lee et al., 1999; Lee et al., 1995). In general, individuals who participate in exercise will have higher proportions of FFM and BMD/BMC when compared to non-active counterparts of the same age, race, ethnicity, and sex. Women who participate in high impact activities have $2-6 \%$ higher bone densities than non-athletic women (Heyward \& Wagner, 2004). Similarly, male recreational runners have higher FFM, observed through lower percentage of FM (12.6\% vs. 
$21.1 \%$, respectively), in comparison to their sedentary counterparts (Penn et al., 1994). With the increase in FFM, the body does not retain as much FM due to a higher resting energy expenditure (REE), which results from muscle and organs having a higher metabolic activity than fat (Gallagher et al., 1998). Current studies have also investigated differences between collegiate athletes (Ballard et al., 2004; Maddalozzo, Cardinal, \& Snow, 2002) and professional athletes (Andreoli et al., 2001) and with non-athletes in various BC measurements including $\% \mathrm{BF}, \mathrm{FFM}$, and BMD (see Table 2.4).

The physiological adaptations of exercise result in healthier, stronger, and leaner individuals with higher FFM and lower FM (Penn et al., 1994). Lower FM is associated with reduced risk of metabolic, cardiovascular, and endocrine diseases (Koster et al., 2011; Lee et al., 1999; Lee et al., 1995). Higher FFM is associated with improved metabolism, $70 \%$ reduced risk of developing sarcopenia (which is the involuntary but physiologic loss of muscle mass that progressively develops during aging (Wagenmakers, 2012)), and 39\% lower risk of overall mortality (Arem et al., 2015; Karstoft \& Pedersen, 2016; Lee et al., 1995; Paffenbarger Jr et al., 1986; Ryu et al., 2013). 
Table 2.4 Comparisons of Percentage of FM (\%BF) Between Athletes and Non-Athletes

\begin{tabular}{|c|c|c|c|c|}
\hline Author (Year) & Gender & $\begin{array}{c}\text { Sport/Non-Athlete } \\
\text { (NA) }\end{array}$ & $\begin{array}{l}\text { Percentage FM } \\
(\% \mathrm{BF})\end{array}$ & $\begin{array}{c}\text { Method of } \\
\text { BC } \\
\text { Assessment }\end{array}$ \\
\hline \multirow{4}{*}{$\begin{array}{l}\text { Andreoli et. al. } \\
\text { (2001) }\end{array}$} & \multirow[t]{4}{*}{ Male } & NA & 16.6 & DXA \\
\hline & & Judo & 10.1 & DXA \\
\hline & & Karate & 11.3 & DXA \\
\hline & & Water Polo & 15.2 & DXA \\
\hline \multirow[t]{2}{*}{$\begin{array}{l}\text { Ballard et. al. } \\
\text { (2004) }\end{array}$} & \multirow[t]{2}{*}{ Female } & NA & $22.5,22.0$ & ADP, DXA \\
\hline & & Athlete & $28.5,28.2$ & ADP, DXA \\
\hline \multirow[t]{3}{*}{$\begin{array}{l}\text { Maddalozzo et. } \\
\text { al. (2002) }\end{array}$} & \multirow[t]{3}{*}{ Female } & NA & $28.8,27.7$ & ADP, DXA \\
\hline & & Gymnastics & $20.9,20.7$ & ADP, DXA \\
\hline & & Volleyball & $20.3,20.9$ & ADP, DXA \\
\hline $\begin{array}{c}\text { El Hage et. al. } \\
\text { (2013) }\end{array}$ & Male & NA & 24.1 & DXA \\
\hline
\end{tabular}

The studies mentioned in this table used DXA, therefore making it easier to compare our study to these. For both men and women, we see nearly $10 \%$ increase in $\% \mathrm{BF}$ from athlete to non-athlete individuals.

Additionally, many athletes have higher BMC and BMD than their non-athlete

counterparts (Heymsfield, 2005). Small sex differences exist, as men tend to have $\sim 10 \mathrm{~kg}$ more FFM than their female counterparts (Caspersen et al., 1985; Sonksen, 2016). With increased FFM and activity, higher BMC/BMD results in reduced risk of osteoporosis and bone fractures, as well as higher calcium, magnesium, and sodium stores (Alfrey \& Miller, 1973; Castiglioni, Cazzaniga, Albisetti, \& Maier, 2013; Jahnen-Dechent \& Ketteler, 2012). These aforementioned positive adaptations to the musculoskeletal system allow athletes to maintain healthy weight and metabolism while reducing their risk of mortality.

Understanding changes in bone, skeletal muscle, and adipose tissue is of great importance in assessing the health and performance of athletes and individuals from non-athletic 
populations. With the improvement in technologies like DXA, CT, and MRI, and sports sciences, there have been changes in our knowledge of body composition standards since the late 1980s and early 1990s. Recently, DXA has been shown to be able to measure VAT as effectively as CT (Kaul et al., 2012), and therefore can be used on athletes to determine body health risks associated with VAT levels (Bosch et al., 2014).

\subsection{Sports Specific Athletes}

Current research in $\mathrm{BC}$ assessment focuses on establishing reference values and finding their association with certain health indices, as well as observing long-term changes in select athletic groups (Stanforth et al., 2014). These studies have observed Olympic level athletes and athletes in sports in which low FM (e.g. Track and Field events), weight-class (Olympic weightlifting), or aesthetics and power (i.e. gymnastics) are of great importance to performance and scoring. Past research observed $\mathrm{BC}$ as a secondary finding when comparing trained, athletic, and non-trained individuals. The literature addresses sports at the elite level (Santos et al., 2014), team sports (Bayios, Bergeles, Apostolidis, Noutsos, \& Koskolou, 2006; Ponce-González, Olmedillas, Calleja-González, Guerra, \& Sanchis-Moysi, 2015; Stanforth et al., 2014), and certain college level athletes (Bolonchuk et al., 1991; Carbuhn et al., 2010; Stanforth et al., 2014). There is currently little documentation that focuses on the $\mathrm{BC}$ of collegiate male basketball and baseball athletes as a primary outcome. Furthermore, there is a lack of information in the literature regarding VAT values in collegiate female athletes.

\subsubsection{MEN'S BASKETBALL}

Basketball is one of the most popular sports around the world. The National Basketball Association (NBA) is the top league that houses the world's best players. Many of the players 
that enter into the NBA are former American collegiate male basketball athletes, primarily from the top tier Division 1 schools. BC assessment on this specific population has not been extensively studied in the last 20 years in the US (Bolonchuk et al., 1991; Hunter et al., 1993), however international studies have been conducted from collegiate to elite (professional) level athletes in basketball (Drinkwater, Pyne, \& McKenna, 2008; Ostojic, Mazic, \& Dikic, 2006; Ponce-González et al., 2015). The studies that were performed previously were comprehensive of NCAA Division 1 teams (Latin et al., 1994) and show that these players were tall with lower FFM than today's players that move onto the NBA (Gonzalez et al., 2013) (see Table 2.5).

Table 2.5 Summary of BC Values for Men's Basketball

\begin{tabular}{|c|c|c|c|c|c|}
\hline Author(Date) & Height & FM & FFM & BMD & VAT \\
\hline $\begin{array}{l}\text { Gonzalez et. } \\
\text { al. (2013) }\end{array}$ & $200.9 \pm 9.4 \mathrm{~cm}$ & $7.2 \pm 1.9 \%$ & $97.16 \mathrm{~kg}$ & N/A & N/A \\
\hline $\begin{array}{l}\text { Bolonchuk et. } \\
\text { al. (1994) }\end{array}$ & $\begin{array}{c}195.4 \pm 10.9 \\
\mathrm{~cm}\end{array}$ & $7.7 \%$ & $\begin{array}{c}82.1 \pm 10.6 \\
\mathrm{~kg}\end{array}$ & N/A & N/A \\
\hline $\begin{array}{l}\text { Latin et. al. } \\
\text { (1994) }\end{array}$ & $\begin{array}{c}195.3 \pm 2.2 \\
\mathrm{~cm}\end{array}$ & $9.4 \pm 2.0 \%$ & $82.3 \pm 4.4 \mathrm{~kg}$ & N/A & N/A \\
\hline $\begin{array}{c}\text { Tavino et. al. } \\
(1995)\end{array}$ & N/A & $13.26 \pm 3.1 \%$ & $78.3 \mathrm{~kg}$ & N/A & N/A \\
\hline
\end{tabular}

This table is adapted from the various sources listed. The values without \pm SD are given values from those sources or are calculated, using values given in the sources, as the author did not provide them in their studies. All of these studies used SKF or UWW as their method to assess BC.

Studies on BC in international male basketball athletes commonly utilize SKF as an assessment tool, which may potentially cause findings to be inaccurate due to the limitations of SKF mentioned in Section 2.3.2. Santos et al. (2014) is one of the few international research groups that used DXA to assess BC and generate reference BC ranges among basketball players and athletes in other sports. The reference values calculated by Santos et. al. may account for ethnically and racially different athletes and therefore be appropriate to use for US collegiate athletic populations which also includes great diversity (see Table 2.6). 
Measurement

Age (years)

Weight $(\mathrm{kg})$

Height (cm)

$\operatorname{BMI}\left(\mathrm{kg} / \mathrm{m}^{2}\right)$

WB BMD $\left(\mathrm{g} / \mathrm{cm}^{2}\right)$

WB FM $(\mathrm{kg})$

WB FM \% (\%BF)

FMI $\left(\mathrm{kg} / \mathrm{m}^{2}\right)$

WB FFM $(\mathrm{kg})$

FFMI $\left(\mathrm{kg} / \mathrm{m}^{2}\right)$
Measured Value

$16-18$

81.9

190.6

22.5

1.299

12.1

14.8

3.38

68.5

18.8

This table was adapted from (Santos et al., 2014). Mean values are presented.

As previously mentioned, another tissue type that has not been explored in Basketball players by investigators is VAT. This compartment has special implications regarding cardiometabolic health as well as psychological health because many environmental and physiological mechanisms can influence the growth of VAT.

\subsubsection{MEN'S BASEBALL}

Like many American team sports, baseball has specific positions that athletes can play, and each position may require different expertise and optimal BC (Spaniol, 2009). Although their respective positions can lead to differences in the physique of these athletes at the elite level, there is generally an overall BC that a majority of baseball players attain. Baseball players expend energy through power-based exercises (Rossi et al., 2017). They rely highly on the 
phosphocreatine and glycolysis systems for active work, which emphasize the need for high FFM during batting, throwing, and sprinting that occurs in spurts throughout the game.

Current literature has not thoroughly investigated the BC of baseball players to establish reference values for this sport at the elite level of Major League Baseball (MLB). This may be due to the nature of the sport, which has skill-based actions (batting, pitching) and power during performance (throwing and sprinting) (Spaniol, 2009). When coaches are assessing a player's performance, they often do not consider a player's physique but rather his playing ability. To better understand the trends of this sports, research and compilation of BC analyses and VAT measurements may be required. Few researchers have observed collegiate student-athletes in baseball but while the heights and weights seem to be homogenous, the breakdown of BC compartments shows differences that may be environmental or genetic (Table 2.7).

Table 2.7 Summary of Mean BC Values of BSB Student-Athletes

\begin{tabular}{cccccc}
\hline $\begin{array}{c}\text { Author } \\
\text { (Year) }\end{array}$ & Height & Weight & FM & FFM & BMD \\
\hline $\begin{array}{c}\text { Loenekke et. } \\
\text { al. (2012)* }\end{array}$ & 1.83 meters & $88.4 \mathrm{~kg}$ & $20.4 \%$ & $70.36 \mathrm{~kg}$ & N/A \\
$\begin{array}{c}\text { Rossi et. al. } \\
(2017)\end{array}$ & N/A & $81.4 \mathrm{~kg}$ & $13.9 \% / 11.5 \mathrm{~kg}$ & $69.9 \mathrm{~kg}$ & N/A \\
$\begin{array}{c}\text { Oates et. al. } \\
(2009)^{*}\end{array}$ & $179.4 \mathrm{~cm}$ & $88.0 \mathrm{~kg}$ & $22.1 \% / 19.9 \mathrm{~kg}$ & $68.3 \mathrm{~kg}$ & $1.413 \mathrm{~g} / \mathrm{cm}^{2}$ \\
\hline
\end{tabular}

This table depicts mean values attained by the respective authors. Authors with an asterisk, $(*)$, designates the use of DXA as a method of measurement for these values.

\subsubsection{WOMEN'S VOLLEYBALL}

Volleyball (VB) is more popular internationally than it is in the US, but it is one of the highest funded sports at the US collegiate level. VB can be considered a power type sport with “specialist" positions of "hitter/blocker" and "setters/defensive" (Stanforth et al., 2014).

Although some investigators have used BC to differentiate between different positions within VB (Anderson, 2010; Stanforth et al., 2014), most research studies examined the team as a whole 
(Bayios et al., 2006; Carbuhn et al., 2010). Most of these players are taller, heavier, and leaner than female athletes from other sports (Ballard et al., 2004; Bayios et al., 2006; Stanforth et al., 2014). Studies that have observed elite level VB players have used SKF or densitometry methods to assess BF\% while most recent studies conducted in the US have used DXA. A summary of these studies shows the ranges of female volleyball players from collegiate to professional level (Table 2.8).

Table 2.8 Summary of Mean BC Values for Women's Volleyball

\begin{tabular}{|c|c|c|c|c|c|}
\hline Author(Date) & Height & FM & FFM & BMD & VAT \\
\hline Anderson et. al (2010) & $\begin{array}{l}175.3 \pm 1.5 \\
\mathrm{~cm}\end{array}$ & $\begin{array}{c}22.1 \pm 1.3 \\
\%\end{array}$ & $54.2 \mathrm{~kg}$ & N/A & N/A \\
\hline Bayios et. al. (2006) & $\begin{array}{c}177.1 \pm 6.5 \\
\mathrm{~cm}\end{array}$ & $23.4 \pm 2.8 \%$ & $\begin{array}{l}53.2 \pm 5.3 \\
\mathrm{~kg}\end{array}$ & N/A & N/A \\
\hline Carbuhn et. al. (2010)* & $\begin{array}{c}181.5 \pm 5.5 \\
\mathrm{~cm}\end{array}$ & $28.4 \pm 4.7 \%$ & $54.5 \mathrm{~kg}$ & $\begin{array}{c}1.292 \pm 0.07 \\
\mathrm{~g} / \mathrm{cm}^{2}\end{array}$ & N/A \\
\hline Ćopić et. al. (2015) & $\begin{array}{l}183.3 \pm 7.7 \\
\mathrm{~cm}\end{array}$ & $17.6 \pm 3.4 \%$ & $58.1 \mathrm{~kg}$ & N/A & N/A \\
\hline Fernández et. al. (2017) & $\begin{array}{c}182.6 \pm 2.5 \\
\mathrm{~cm}\end{array}$ & $17.1 \pm 3.3 \%$ & $59.4 \mathrm{~kg}$ & N/A & N/A \\
\hline $\begin{array}{l}\text { Maddalozzo et. al. } \\
(2002)^{*}\end{array}$ & $\begin{array}{c}1.79 \pm 0.005 \\
\mathrm{~m}\end{array}$ & $\begin{array}{c}20.9 \pm 2.7 \\
\%\end{array}$ & $56.4 \mathrm{~kg}$ & N/A & N/A \\
\hline $\begin{array}{c}\text { Martin-Matillas et. al. } \\
\text { (2014) }\end{array}$ & $\begin{array}{c}179.8 \pm 7.1 \\
\mathrm{~cm}\end{array}$ & $24.0 \pm 3.1 \%$ & $\begin{array}{c}54.9 \pm 5.7 \\
\mathrm{~kg}\end{array}$ & N/A & N/A \\
\hline Nikolaidis et. al. (2012) & $\begin{array}{l}175.6 \pm 6.8 \\
\mathrm{~cm}\end{array}$ & $\begin{array}{l}22.1 \pm \\
3.32 \%\end{array}$ & $\begin{array}{c}52.03 \pm 3.39 \\
\mathrm{~kg}\end{array}$ & N/A & N/A \\
\hline Stanforth et. al. (2014)* & $\begin{array}{l}181.1 \pm 2.0 \\
\mathrm{~cm}\end{array}$ & $22.7 \pm 0.7 \%$ & $56.2 \mathrm{~kg}$ & N/A & N/A \\
\hline Santos et. al. (2014)* & $174.5 \mathrm{~cm}$ & $25.6 \%$ & $49.6 \mathrm{~kg}$ & $1.206 \mathrm{~g} / \mathrm{cm}^{2}$ & N/A \\
\hline
\end{tabular}

This table is adapted from the various sources listed. The values without \pm SD are given values from those sources. FFM values without \pm SD are calculated from the sources as the author did not provide FFM in their studies. The studies with an asterisk, $(*)$, are studies that used DXA as their methods for BC assessment. 


\subsubsection{WOMEN'S SOCCER}

Soccer players are generally powerful, fast, and lean. With the advancements in sports science, soccer players have become quicker and stronger while being able to retain longevity in their playing career (Datson et al., 2014). Although soccer has been deemed as an endurancetype sport, these athletes do not share physiques of long-distance runners, cyclists, or swimmers (Stanforth et al., 2014). All types of running distances and speeds are used in the game, and therefore different energy expenditures are observed (Datson et al., 2014).

Women's soccer is evaluated frequently in sport science, sport psychology, and sport nutrition studies in the US (Arena, McLaughlin, Nguyen, Smoliga, \& Ford, 2017; Johnson, 2016; Reed, De Souza, \& Williams, 2013). There may be varying reasons for soccer being studied more often than other sports, but this allows for a greater body of knowledge when comparing and adding BC assessments. Currently, there is little to no assessment of VAT in female soccer players at the collegiate level using DXA (see Table 2.9). To the investigator's knowledge, this study will be the first to report VAT in women's soccer players. 
Table 2.9 Summary of Mean BC Values for Women's Soccer

\begin{tabular}{|c|c|c|c|c|c|}
\hline Author(Date) & Height & FM & FFM & BMD & VAT \\
\hline $\begin{array}{l}\text { Arena et. al. } \\
\text { (2017)* }\end{array}$ & $\begin{array}{c}1.68 \pm 0.06 \\
\mathrm{~m}\end{array}$ & N/A & N/A & N/A & N/A \\
\hline $\begin{array}{l}\text { Ballard et. al. } \\
(2004)^{*}\end{array}$ & N/A & $22.0 \pm 4.7 \%$ & N/A & N/A & N/A \\
\hline $\begin{array}{l}\text { Brännström et. } \\
\text { al. (2017)* }\end{array}$ & $\begin{array}{c}1.65 \pm 0.04 \\
\mathrm{~m}\end{array}$ & $25.1 \%$ & 42.8 & $\begin{array}{c}1.53 \pm 0.78 \\
\mathrm{~g} / \mathrm{cm}^{2}(\mathrm{Z}- \\
\text { score })\end{array}$ & N/A \\
\hline $\begin{array}{l}\text { Datson et. al. } \\
\quad(2014)\end{array}$ & $1.61-1.7 \mathrm{~m}$ & $14.6-20.1 \%$ & $45.7 \pm 3.9 \mathrm{~kg}$ & N/A & N/A \\
\hline $\begin{array}{l}\text { Esco et. al. } \\
(2015)^{*}\end{array}$ & $166.1 \pm 7.1 \mathrm{~cm}$ & $\begin{array}{c}25.86 \pm \\
5.56 \%\end{array}$ & $\begin{array}{c}46.08 \pm 5.91 \\
\mathrm{~kg}\end{array}$ & N/A & N/A \\
\hline $\begin{array}{l}\text { Ferry et. al. } \\
(2011)^{*}\end{array}$ & $\begin{array}{c}165.0 \pm 5.8 \\
\mathrm{~cm}\end{array}$ & $\begin{array}{l}21.01 \pm \\
3.92 \%\end{array}$ & $\begin{array}{l}44.99 \pm \\
4.11 \mathrm{~kg}\end{array}$ & $\begin{array}{c}1.19 \pm 0.07 \\
\mathrm{~g} / \mathrm{cm}^{2}\end{array}$ & N/A \\
\hline $\begin{array}{l}\text { Minett et. al. } \\
(2017)^{*}\end{array}$ & $\begin{array}{c}165.1 \pm 1.3 \\
\mathrm{~cm}\end{array}$ & $22 \pm 0.7 \%$ & $50 \mathrm{~kg}$ & N/A & N/A \\
\hline $\begin{array}{l}\text { Randers et. al. } \\
(2013)^{*}\end{array}$ & $172 \pm 5 \mathrm{~cm}$ & $20.2 \%$ & $50.4 \pm 3.3 \mathrm{~kg}$ & N/A & N/A \\
\hline $\begin{array}{l}\text { Stanforth et. al. } \\
(2014)^{*}\end{array}$ & $\begin{array}{c}166.3 \pm 0.9 \\
\mathrm{~cm}\end{array}$ & $24.0 \pm 0.5 \%$ & $47.2 \mathrm{~kg}$ & N/A & N/A \\
\hline
\end{tabular}

This table is adapted from the various sources listed. Some of the values without \pm SD are given values from those sources or are calculated, using the given values from sources, as the author did not provide the information in their studies. The studies with an asterisk, $(*)$, are studies that used DXA as their methods for BC assessment. 


\section{Methods}

\subsection{Objective}

Collegiate athletics are very popular, but student-athletes typically perform in competitive environments that include rigorous and demanding training regimens, which tend to induce significant physical and metabolic changes. Given the age and the challenges of being a college athlete, it is important to assess the changes in the context of the athletes' health, performance, and the role of BC. The objectives of this study are to use: 1) determine preseason differences in $\mathrm{BC}$ between select Division 1 sports and 2) changes in $\mathrm{BC}$ over a competitive season in two sports.

DXA was used for scanning and analysis factors, safety, and output capabilities. The study included previously performed DXA scans of NCAA Division-I Baseball (BSB), Men's Basketball (MBB), Women's Volleyball (VB), and Women's Soccer (WSOC) student-athletes from 2013 to 2016. This combination of athletes provides important information related to the health and body composition in the context of gender and exercise-mode differences. In addition, repeated measurements of $\mathrm{BSB}$ and $\mathrm{MBB}$ facilitated examination of the effects the competitive season in these two sports.

For this study, a total of 106 student-athletes were assessed. The teams and their players included: Men's Basketball (MBB) $n=23$, Men's Baseball $(\mathrm{BSB}) \mathrm{n}=38$, Women's volleyball (VB) $n=15$, and Women's Soccer (WSOC) $n=29$. The age of the student-athletes ranged from 18 - 22 years. Data on MBB and BSB players was available from two subsequent seasons. Participation in this study was voluntary. Exclusion criteria included injury prior to the season, choosing not to participate in the study, redshirt or no participation during the season. Scans 
were taken at the beginning of the season, which was in the general preparation phase for each sport. End-season scans were performed for the men's sports at the end of the sport's respective season. The California Polytechnic State University-San Luis Obispo's Institutional Review Board approved this study prior to its initiation. Subjects were informed of the benefits and risks of the investigation prior to signing an institutionally approved informed consent to be a participant in the study.

\subsection{Assessment of Anthropometrics and Body composition (BC)}

All athletes reported to the Cal Poly Nutrition and Health Assessment Lab for DXA testing. Basic anthropometrics - height and weight - were measured prior to the DXA scan using a stadiometer and calibrated medical beam scale, respectively. It was requested that the studentathletes prepare by being well-rested, well-hydrated, and fasted for all scans. Scans were performed in the morning or a few hours before practice. Athletes wore the appropriate clothing, removed as much jewelry as possible, and females had a negative pregnancy test. Full-body DXA scans were done using a GE Healthcare Lunar iDXA (GE Healthcare, Madison, WI, USA). A technician trained by GE Lunar DXA personnel performed the scans using standardized positioning protocols and software steps. The same technician did all scans for the study using the same iDXA. There were no hardware or software changes to the system during the study. The iDXA passed calibration testing using a QA block phantom (GE Healthcare) every day prior to scans. No calibration drift of the instrument was observed over the course of the study.

The DXA data were obtained using EnCORE software (GE Healthcare) version 14.1. DXA values from EnCORE used for the study included: Total Mass (fat mass + lean soft tissue + bone mineral content); Fat Mass (all adipocytes); Lean Soft Tissue (all tissues not including bone 
and fat mass); Fat-Free Mass (lean soft tissue + bone mineral content); Percentage of Fat Mass (fat mass / total mass, also referred to as \%BF); Bone Mineral Density (expressed as Bone Mineral Density, g/cm² - Z-Scores).

The CoreScan software (GE Healthcare) tool was used to estimate visceral adipose tissue (VAT) amounts. CoreScan was developed recently (Kaul et al. 2012) as a means to quantify the volume of VAT using the iDXA and values have been shown to be similar to using CT scans for VAT assessment. DXA values derived from CoreScan and used for the study included VAT (in volume and weight units). No additional techniques or time were required to obtain the VAT values other than utilize the CoreScan tool of the iDXA software.

Mass indices were calculated by taking the mass of interest, in kilograms, and dividing by the squared height, in meters, as seen with body mass index (BMI) (see Section 2.2.2). Using the distributive properties of division, BMI is to equal the sum of FMI and FFMI.

$$
\mathrm{BMI}=\mathrm{FMI}+\mathrm{FFMI}
$$

where,

$$
\begin{aligned}
\mathrm{BMI} & =\frac{\text { Body Mass (in kilograms) }}{\text { Height }^{2} \text { (in meters) }} \\
\mathrm{FMI} & =\frac{\text { Fat Mass (in kilograms) }}{\text { Height }^{2} \text { (in meters) }} \\
\mathrm{FFMI} & =\frac{\text { Fat Free Mass (in kilograms) }}{\text { Height }^{2} \text { (in meters) }}
\end{aligned}
$$

\subsection{Statistical Analysis}

To determine whether the variable means significantly differed for at least two of the athletic groups, multivariate analysis of variance (MANOVA) was performed. After the overall MANOVA test was rejected (Wilks test statistic $<0.05$, p-value $<0.001$ ), follow-up one-way 
analysis of variance (ANOVA) tests were used to identify variables that had significantly different means for at least two of the sports groups. Finally, for those ANOVA tests that were rejected, Tukey’s HSD post-hoc tests were performed to determine which sports groups had significantly different means with an alpha set to 0.05 . Paired t-tests were used when analyzing differences in the seasonal changes in BC of MBB and BSB. Alpha level was set to 0.00625 to account for the multiple paired t-tests. All analyses were performed in R, version 3.5.1. 


\section{Results}

\subsection{Anthropometrics}

We observed differences in the means of height and weight from whole-body measurements. Men's teams were significantly heavier than women's teams $(\mathrm{p}<0.01)$ and VB players were heavier $(160.6 \pm 18.1 \mathrm{lb})$ than WSOC players $(140.4 \pm 12.0 \mathrm{lb})(\mathrm{p}<0.01)$. Heights were significantly different between all groups. MBB group was the tallest and WSOC group was the shortest, all differences of the means between the groups were significant $(\mathrm{p}<0.01)$. BMI differences were observed between genders with men's teams being significantly higher than the women's teams $(\mathrm{p}<0.01)$. These results are presented in Table 4.1 below. Multivariate analyses of variance were used on all variables to reduce Type I error.

Table 4.1 Participant Anthropometrics

\begin{tabular}{cccccc}
\hline Sport & Height (in) & Height (cm) & Weight (lb) & Weight (kg) & $\begin{array}{c}\text { BMI } \\
\left(\mathbf{k g} / \mathbf{m}^{2}\right)\end{array}$ \\
\hline MBB & $75.6( \pm 3.1)^{\mathrm{a}, \mathrm{b}, \mathrm{c}}$ & $191.9( \pm 7.8)^{\mathrm{a}, \mathrm{b}, \mathrm{c}}$ & $202.1( \pm 26.5)^{\mathrm{b}, \mathrm{c}}$ & $91.8( \pm 12.1)^{\mathrm{b}, \mathrm{c}}$ & $24.8( \pm 2.0)^{\mathrm{b}, \mathrm{c}}$ \\
BSB & $72.7( \pm 2.1)^{\mathrm{b}, \mathrm{c}}$ & $184.7( \pm 5.4)^{\mathrm{b}, \mathrm{c}}$ & $193.4( \pm 16.2)^{\mathrm{b}, \mathrm{c}}$ & $87.9( \pm 18.7)^{\mathrm{b}, \mathrm{c}}$ & $25.8( \pm 1.6)^{\mathrm{b}, \mathrm{c}}$ \\
VB & $70.2( \pm 4.0)^{\mathrm{c}}$ & $178.4( \pm 10.1)^{\mathrm{c}}$ & $160.6( \pm 18.1)^{\mathrm{c}}$ & $73.0( \pm 8.2)^{\mathrm{c}}$ & $22.9( \pm 1.1)$ \\
WSOC & $66.2( \pm 2.1)$ & $168.2( \pm 5.4)$ & $140.4( \pm 12.0)$ & $63.8( \pm 5.5)$ & $22.6( \pm 1.9)$ \\
\hline
\end{tabular}

Presented as Mean( \pm SD). MBB, Men's Basketball; BSB, Baseball; VB, Volleyball; WSOC, Women's Soccer. Superscripts indicate the following:

a, significantly different from baseball

b, significantly different from volleyball

c, significantly different from soccer.

\subsection{BC Parameters}

Observed means of BC data of Fat Mass (FM), Fat-Free Mass (FFM), Bone Mineral Density (BMD), and Visceral Adipose Tissue (VAT) from the DXA scans are summarized in 
Table 4.2. Graphical representations of each tissue type have been provided in the figures that follow for ease of the reader to visualize the information.

Table 4.2 Means of the Body Composition Measurements for the Various Sports MBB BSB VB $\quad$ WSOC

\begin{tabular}{ccccc}
\hline FM (lb) & $30.0( \pm 10.5)^{\mathrm{a}, \mathrm{b}}$ & $36.1( \pm 8.0)^{\mathrm{b}}$ & $45.0( \pm 8.7)^{\mathrm{c}}$ & $35.0( \pm 7.1)$ \\
FM (kg) & $13.7( \pm 4.8)^{\mathrm{a}, \mathrm{b}}$ & $16.4( \pm 3.7)^{\mathrm{b}}$ & $20.4( \pm 3.9)^{\mathrm{c}}$ & $15.9( \pm 3.2)$ \\
FFM (lb) & $172.0( \pm 21.2)^{\mathrm{a}, \mathrm{b}, \mathrm{c}}$ & $157.2( \pm 18.1)^{\mathrm{b}, \mathrm{c}}$ & $115.7( \pm 11.2)$ & $105.5( \pm 10.4)$ \\
FFM (kg) & $78.2( \pm 9.6)^{\mathrm{a}, \mathrm{b}, \mathrm{c}}$ & $71.5( \pm 8.2)^{\mathrm{b}, \mathrm{c}}$ & $52.6( \pm 5.1)$ & $47.9( \pm 4.7)$ \\
VAT (lb) & $0.54( \pm 0.26)^{\mathrm{b}, \mathrm{c}}$ & $0.48( \pm 0.32)^{\mathrm{b}, \mathrm{c}}$ & $0.18( \pm 0.21)$ & $0.11( \pm 0.13)$ \\
FMI & $3.7( \pm 1.3)^{\mathrm{a}, \mathrm{b}, \mathrm{c}}$ & $4.8( \pm 1.2)^{\mathrm{b}, \mathrm{c}}$ & $6.4( \pm 0.9)$ & $5.6( \pm 1.3)$ \\
FFMI & $21.2( \pm 1.4)^{\mathrm{b}, \mathrm{c}}$ & $20.9( \pm 1.8)^{\mathrm{b}, \mathrm{c}}$ & $16.5( \pm 0.8)$ & $16.9( \pm 1.3)$ \\
\hline
\end{tabular}

Presented as Mean( \pm SD). MBB, Men's Basketball; BSB, Baseball; VB, Volleyball; WSOC, Women's Soccer. Superscripts indicate the following:

a, significantly different from baseball

b, significantly different from volleyball

c, significantly different from soccer.

Figure 4.1 shows the difference between means, with standard deviation bars, of the FM, in pounds. Values were not adjusted for body height or body mass. The VB players had the highest amount of FM $(45.0 \pm 8.7 \mathrm{lb})$ when compared to the other teams $(\mathrm{p}<0.01)$. BSB players had higher amounts of FM (36.1 $\pm 8.0 \mathrm{lb}$. $)$ than the MBB players $(30.0 \pm 10.5 \mathrm{lb}).(\mathrm{p}<0.05)$. BSB and WSOC had similar amounts of FM (36.1 \pm 8.0 vs. $35.0 \pm 7.1$ lb., respectively). Women generally have more FM than men such that hypothesis I.1. is rejected due to WSOC, BSB, and MBB having FM amounts that are not significantly different. 


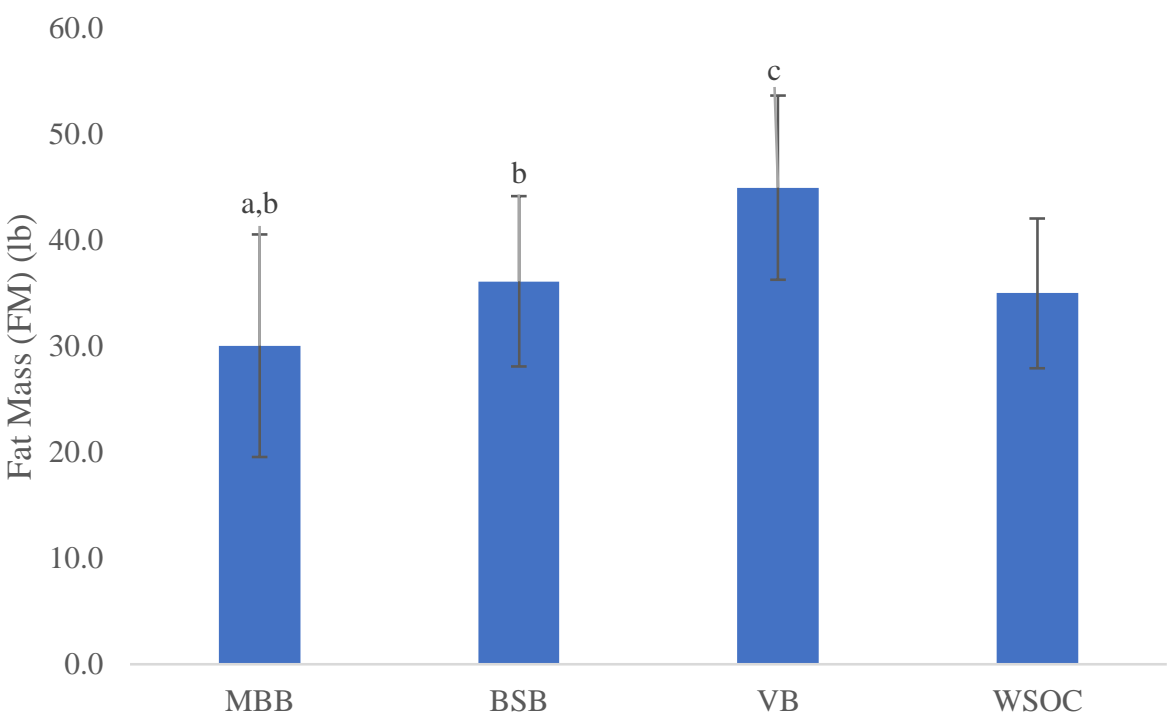

Figure 4.1 Fat Mass (FM) Measured by DXA

MBB $-30 \pm 10.5$ lbs. BSB $36.1 \pm 8.0$ lbs. VB $-45.0 \pm 8.7$ lbs. WSOC $-35.0 \pm 7.1$ lbs. Superscripts indicate the following:

a, significantly different from baseball

b, significantly different from volleyball

c, significantly different from soccer.

When we compared percentages of FM (\%BF) between the sports (hypothesis I.3.), we noticed that all sports have significantly different \%BF except between VB and WSOC which was trending $(\mathrm{p}=0.065)$, as seen in Figure 4.2. Men generally have less $\%$ BF than women, as stated previously. 


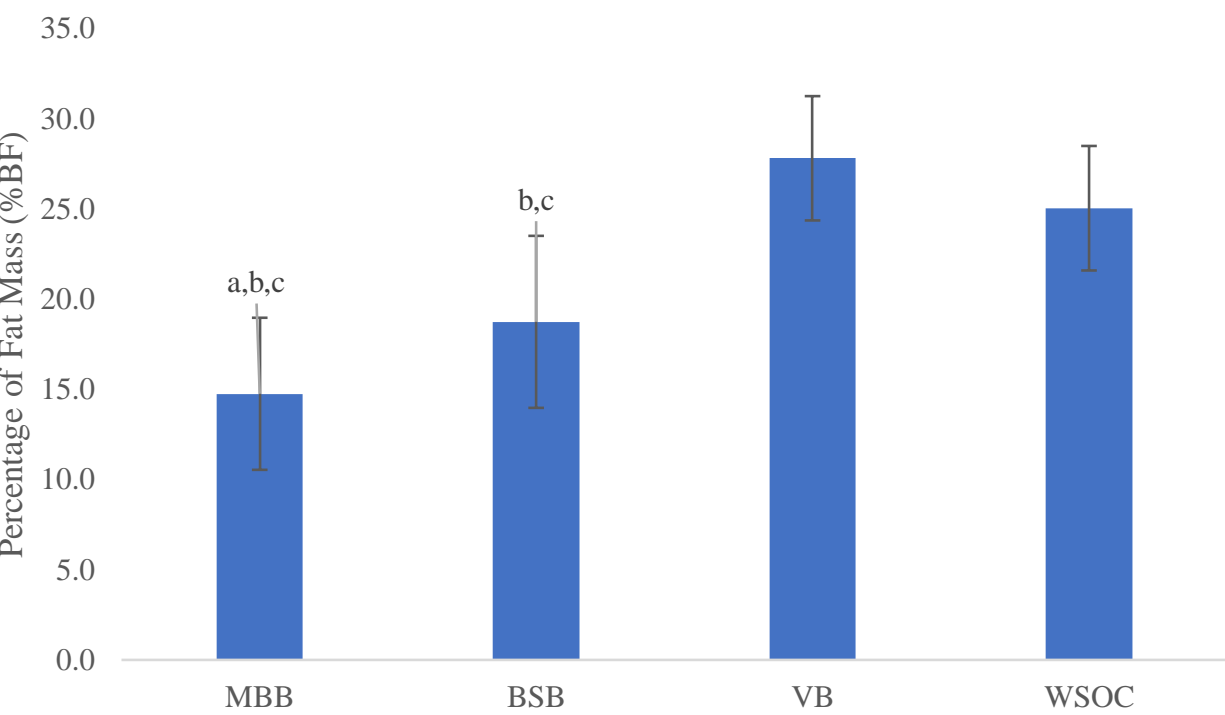

\section{Figure 4.2 Percentage of Fat Mass (\% BF) Measured by DXA}

MBB $-14.8 \pm 4.2 \%$. BSB $18.7 \pm 4.6 \%$. VB $-27.8 \pm 3.4 \%$. WSOC $-25.0 \pm 3.5 \%$. Superscripts indicate the following:

a, significantly different from baseball

b, significantly different from volleyball

c, significantly different from soccer.

Figure 4.3 displays the differences in the means of FFM between the sports. MBB was

shown to have the highest mean of FFM $(172.0 \pm 21.2 \mathrm{lb}$.) when compared to other sports

$(\mathrm{p}<0.01)$. FFM differences were not found to be significantly different between VB $(115.7 \pm 11.2$

lb.) and WSOC players $(105.5 \pm 10.4 \mathrm{lb})(\mathrm{p}>0.05)$. FFM is generally higher in men's sport

(Sonksen, 2016). Differences were observed within male student-athletes which rejects

hypothesis I.2 as we did not find significant differences between the groups. 


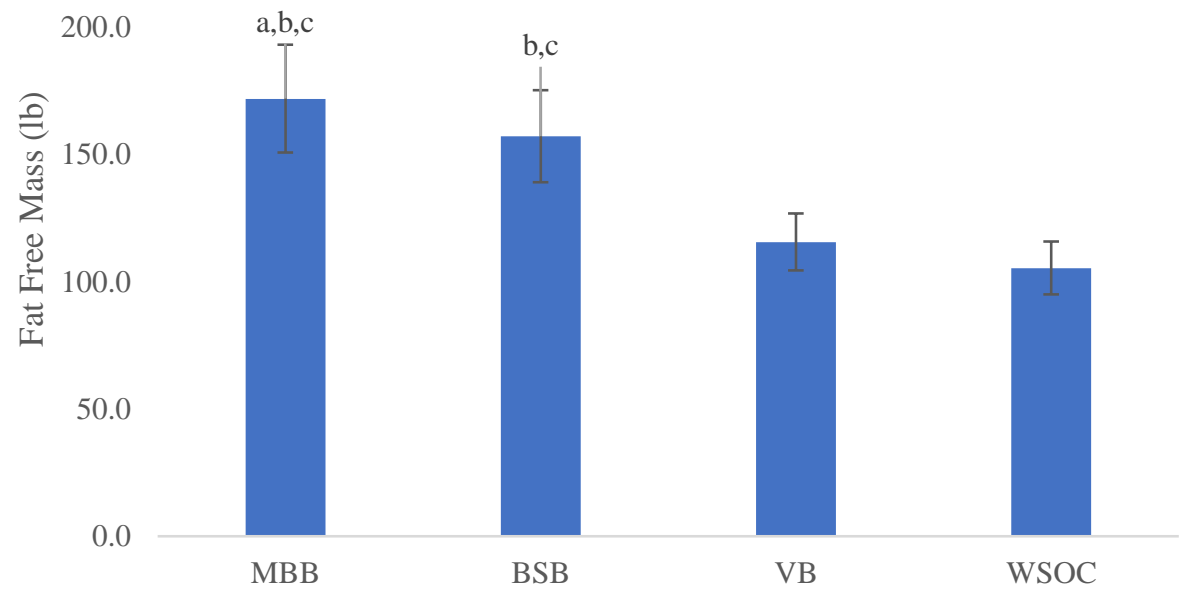

Figure 4.3 Amounts of Fat-Free Mass (FFM) in Pounds as Measured by DXA. MBB $-172 \pm 21.2 \mathrm{lbs}$. BSB $157.2 \pm 18.2 \mathrm{lbs}$. VB $-115.7 \pm 11.2 \mathrm{lbs}$. WSOC $-105.5 \pm 10.4 \mathrm{lbs}$. Superscripts indicate the following:

a, significantly different from baseball

b, significantly different from volleyball

c, significantly different from soccer.

Figure 4.4 illustrates the differences in the means of BMD between the sports. Bone mineral density (BMD), in Z-scores, were not significantly different between the means of each sport as seen in Figure 4.4 ( $p>0.05)$. The observed values show that the BMD values are greater than the average BMD Z-score values (-1 to 1). A general trend was observed between the sport types with court sports (MBB, 2.9, and $\mathrm{VB}, 2.7)$ having a higher BMD value than field sports (BSB, 2.5, and WSOC, 2.4). While each of the sports do have different mean values, Figure 4.4 illustrates that there is no significant difference between sports for BMD, thus rejecting hypothesis I.4. 


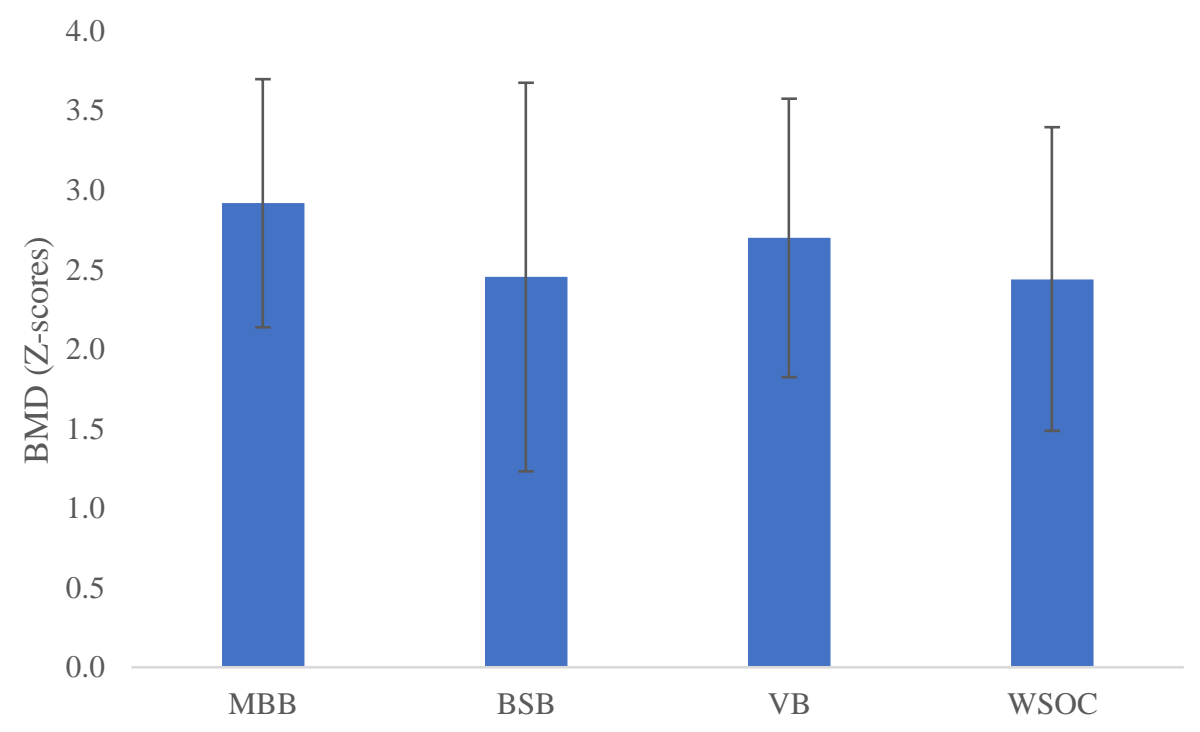

Figure 4.4 Distribution of Bone Mineral Density Measured by DXA.

Athletes show no significant differences but trends show increased BMD in court-based sports than fieldbased. MBB $-2.9 \pm 0.8$. BSB $2.5 \pm 1.2$. VB $-2.7 \pm 0.9$. WSOC $-2.4 \pm 1.0$ BMD Z-Scores were well above normal ranges provided by GE Healthcare.

\subsection{Visceral Adipose Tissue}

VAT values were attained using Corescan software (GE Healthcare) on the iDXA. These values are given in total area (squared inches) and weight (pounds), of which weight was used in the analysis and comparison between sports. Figure 4.5 illustrates the differences between the sports; it showed that MBB had the highest amount of VAT overall $(0.54 \pm 0.26 \mathrm{lb}$.). While MBB and WSOC are endurance-based sports, they do not share proportional amounts of VAT thus rejecting hypothesis I.5. In comparison to the women's teams, the men's teams had significantly higher amounts of VAT. 


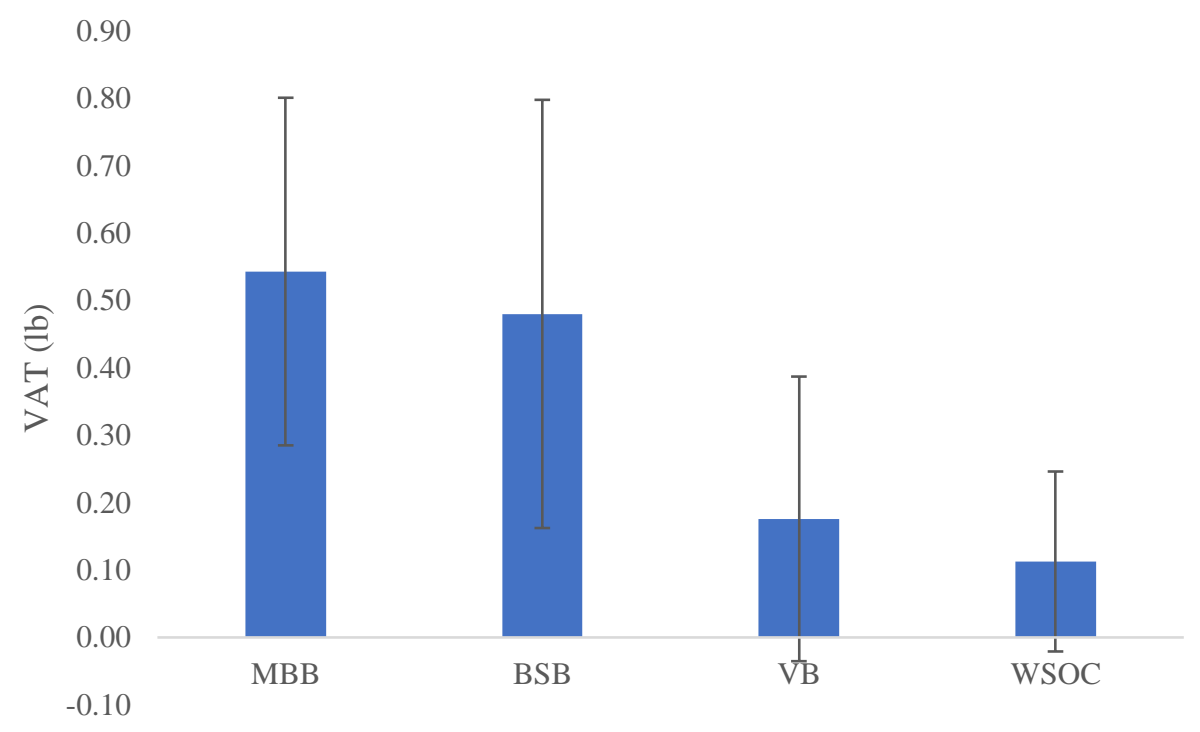

Figure 4.5 Total VAT in Pounds as measured by DXA.

MBB $-0.54 \pm 0.26 \mathrm{lbs}$. BSB $0.48 \pm 0.32 \mathrm{lbs}$. VB $-0.18 \pm 0.21 \mathrm{lbs}$. WSOC $-0.11 \pm 0.13 \mathrm{lbs}$.

Superscripts indicate the following:

a, significantly different from baseball

b, significantly different from volleyball

c, significantly different from soccer.

Figure 4.6 shows another interpretation of VAT as a percentage of FM. Again, MBB was significantly different with the highest percentage of VAT (\%VAT) $(2.0 \%)$ relative to FM when compared to the other sports (BSB: 1.4\%; VB: 0.4\%; WSOC: 0.3\%). We observed opposing correlation of VAT and \%BF between genders that lower \%BF allows for lower \%VAT; this rejects hypothesis 1.6 in male student-athletes but accepts the hypothesis in female student athlete. In comparison to the women's teams, the men's teams had higher amounts of VAT. 


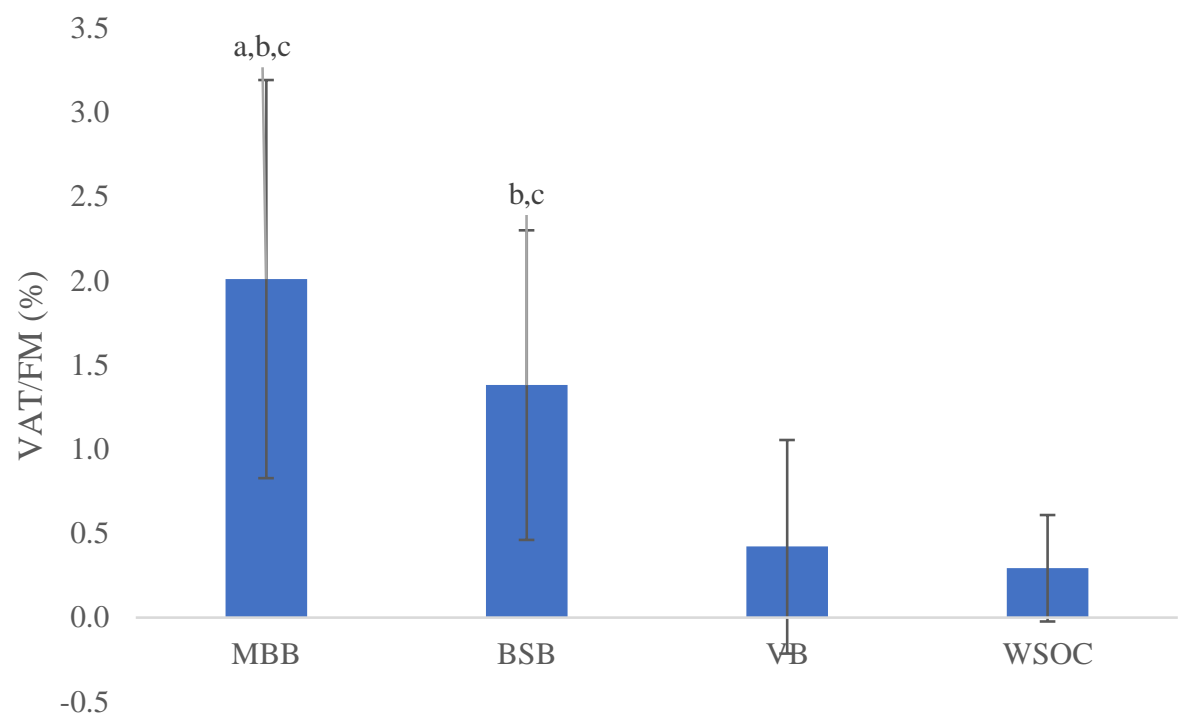

Figure 4.6 VAT represented as a Percentage of FM

VAT has been divided by FM in pounds to represent the percentage of total amount of FM. MBB $-2.0 \pm 1.2 \%$. BSB $1.4 \pm 0.9 \%$. VB $-0.4 \pm 0.6 \%$. WSOC $-0.3 \pm 0.3 \%$.

Superscripts indicate the following:

a, significantly different from baseball

$\mathrm{b}$, significantly different from volleyball

c, significantly different from soccer.

\subsection{Indices of fat and lean mass}

FMI and FFMI is calculated by taking the mass of fat or fat-free mass, in kilograms, and dividing by the height, in meters, squared. MBB has the lowest FMI values $\left(3.7 \pm 1.3 \mathrm{~kg} / \mathrm{m}^{2}\right)$ with VB $\left(6.4 \pm 0.9 \mathrm{~kg} / \mathrm{m}^{2}\right)$ having the highest FMI value as seen in Figure 4.7. 


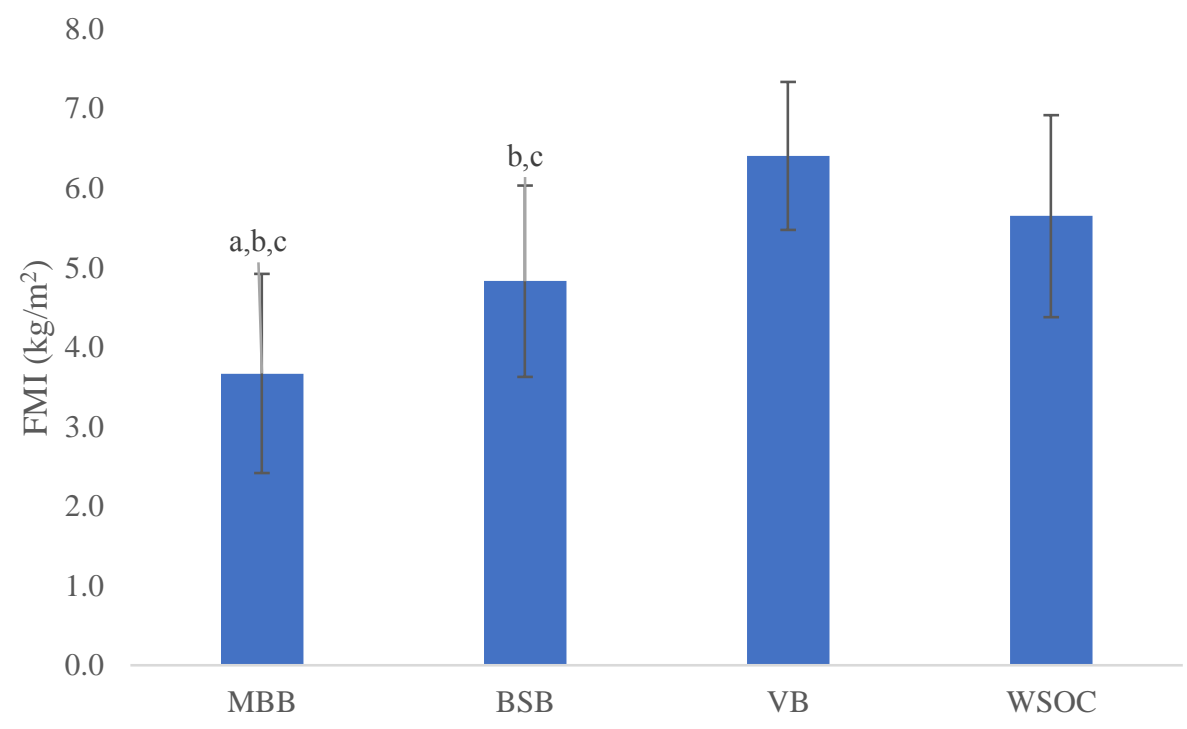

Figure 4.7 Distribution of Fat Mass Index (FMI) in $\left(\mathrm{kg} / \mathrm{m}^{2}\right)$.

MBB $-3.7 \pm 1.3 \mathrm{~kg} / \mathrm{m}^{2}$. BSB $4.8 \pm 1.2 \mathrm{~kg} / \mathrm{m}^{2}$. VB $-6.4 \pm 0.9 \mathrm{~kg} / \mathrm{m}^{2}$. WSOC $-5.6 \pm 1.3 \mathrm{~kg} / \mathrm{m}^{2}$. Superscripts indicate the following:

a, significantly different from baseball

b, significantly different from volleyball

c, significantly different from soccer.

Women's sports were not significantly different when comparing the means of the FMI values ( $\mathrm{p}>0.05)$. When comparing with women's sports, men's sports had higher FFMI values $(\mathrm{p}<0.001)$ seen in figure 4.8. Men's sports are at an average of $3.9 \mathrm{~kg} / \mathrm{m}^{2}$ higher than women's sports. 


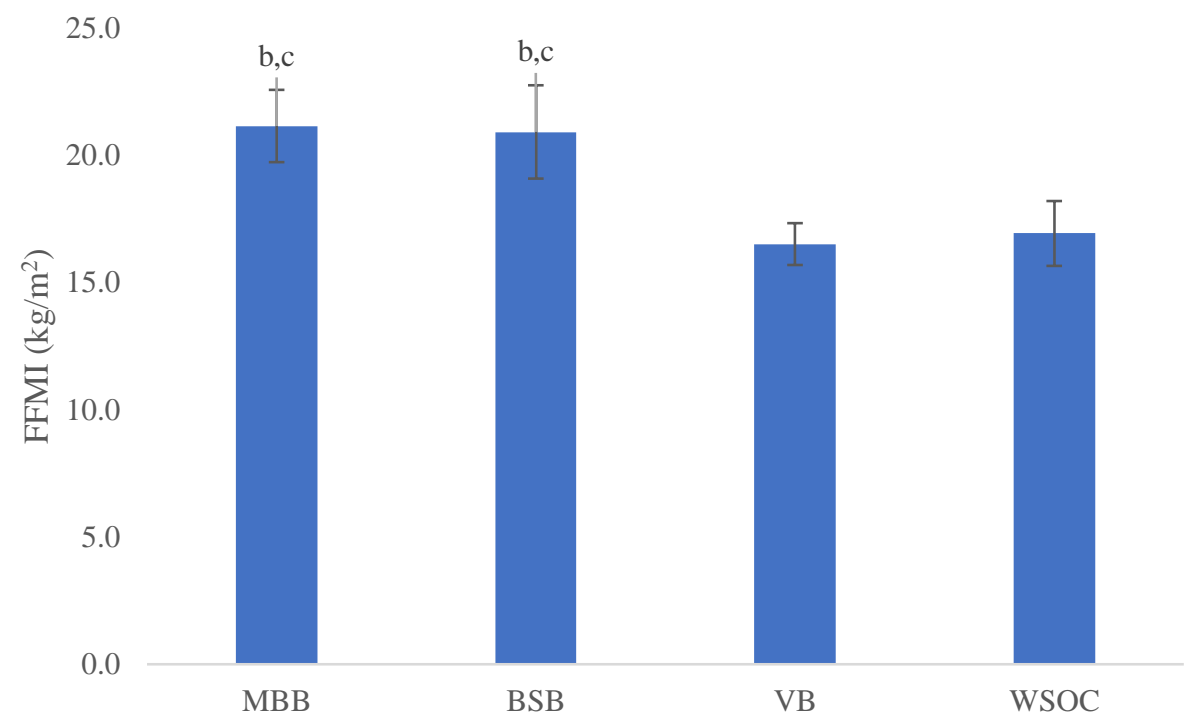

Figure 4.8 Distribution of Fat-Free Mass Index (FFMI) in Various Sports in $\left(\mathrm{kg} / \mathrm{m}^{\mathbf{2}}\right)$. MBB $-21.2 \pm 1.4 \mathrm{~kg} / \mathrm{m}^{2}$. BSB $20.9 \pm 1.8 \mathrm{~kg} / \mathrm{m}^{2}$. VB $-16.5 \pm 0.8 \mathrm{~kg} / \mathrm{m}^{2}$. WSOC $-16.9 \pm 1.3 \mathrm{~kg} / \mathrm{m}^{2}$. Superscripts indicate the following:

a, significantly different from baseball

b, significantly different from volleyball

c, significantly different from soccer.

\subsection{BC Changes in Men's Sports over a Competitive Season}

The means for the $\mathrm{BC}$ variables for both sports across a competitive season are shown in Table 4.3. The only major observation that showed a significant increase was BMD, which rejects hypothesis II.3. In figure 4.9, BMD is shown and was found to be significantly higher at the end of the season in MBB but not in BSB ( $p=0.0343)$, while collectively the means of all the male athletes show an increase in BMD. While the preseason scans of all sports showed significant differences in FM between male sports, this was not apparent when comparing the teams over the season. Trends of increased weight and decreased fat mass were observed as well $(\mathrm{p}=0.071$ and $\mathrm{p}=0.129$, respectively). There were no other significant changes in other variables in MBB and BSB (p>0.05). While we observed the trends of hypotheses II.1 and II.2, we did not 
see significant changes, thus rejecting these hypotheses. Our last hypothesis (II.4) was also rejected as we observed both teams increase their VAT accumulation but MBB has higher accumulation than BSB.

Table 4.3 Means of the Body Weight and Composition in MBB and BSB Before and After the Season

\begin{tabular}{lcccc}
\hline & Weight (lb) & FM (lb) & VAT (lb) & BMD \\
\hline MBB - Pre & $202.83( \pm 26.9)$ & $30.03( \pm 10.6)$ & $0.52( \pm 0.19)$ & $2.79( \pm 0.9)$ \\
MBB - End & $205.86( \pm 26.2)$ & $28.92( \pm 10.5)$ & $0.56( \pm 0.21)$ & $2.99( \pm 0.9)^{\mathrm{A}}$ \\
BSB - Pre & $192.02( \pm 11.0)$ & $34.81( \pm 5.6)$ & $0.41( \pm 0.3)$ & $2.39( \pm 1.0)$ \\
BSB - End & $192.06( \pm 9.8)$ & $34.19( \pm 5.9)$ & $0.41(+0.30)$ & $2.51( \pm 1.0)$ \\
Overall -Pre & $197.43( \pm 21.0)$ & $32.42( \pm 8.7)$ & $0.46( \pm 0.28)$ & $2.59( \pm 1.0)$ \\
Overall - End & $198.96( \pm 20.7)$ & $31.55( \pm 8.8)$ & $0.49( \pm 0.26)$ & $2.75( \pm 1.0)^{\mathrm{A}}$ \\
\hline
\end{tabular}

Body weights were obtained by a medically calibrated balance-beam scale. "A," significant when compared to preseason $-\mathrm{p}<0.00625$.

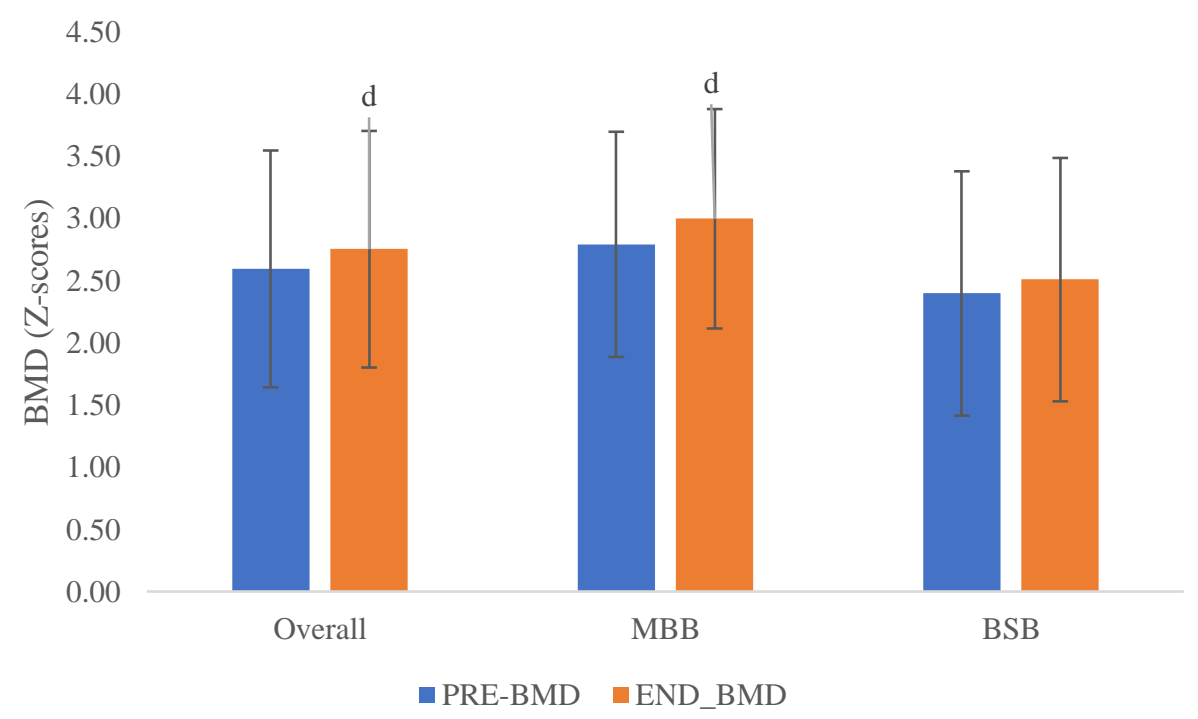

Figure 4.9 Distribution of Bone Mineral Density in MBB and BSB Over a Season d, significantly different from pre-season scans 


\section{Discussion}

The purpose of this study was to evaluate the body composition (BC) of athletes in various sports at the US collegiate level using DXA and anthropometry. Analyses were done at the start of each season for each sport and repeated after a competitive season for the two of the sports. Using DXA captures the variations of body composition including BMD in athletes that

are generally caused by a variety of different mechanical stressors as well as ethnicity, genetics, and nutritional intake of the athlete. It should be noted that BMD is an important body composition characteristic in athletes and non-athletes, and can be measured by DXA (or CT), but not most commonly used BC analysis methods. Moreover, DXA BC analysis data differs from other methods, such as UWW, ADP, BIA, and SKF so it is important to consider the methods used when comparing findings from various studies. In addition, another unique and valuable benefit of DXA scans is that recently-developed software estimates VAT, a potentially very important effector of health. An athlete's performance and health may benefit from a better understanding and recording their BC values such as FM, FFM, VAT, and BMD. Therefore, we believe the present study provides important information, and to the author's knowledge, novel information regarding BC of select Division 1 NCAA athletes.

\subsection{Height}

Over the last few decades, robust changes in sports-specific training, strength training, and nutritional programs may have improved physiological adaptations in athletes. In general, current generations are taller and larger in stature than the previous generations and this can affect BC values such as the estimation of FFM (Sonksen, 2016). At the same time, it is commonly accepted that athletes are taller and have higher FFM than their age-matched non- 
athlete counterparts (Sonksen, 2016). All of the sports observed in this study, except MBB, followed this trend of younger generations being taller than the previous. In this study, BSB student-athletes are slightly taller (72.7 inches) on average than participants of the studies done previously that reported values of 70.4 inches (Loenneke et al., 2013) and 71.6 inches (Oates \& Oates, 2009; Oates, Oates, \& Barden, 2009). VB student-athletes in our study were observed to be taller $(70.2 \pm 4.0$ inches $[178.4 \pm 10.1 \mathrm{~cm}])$ than older and international populations (see Table 2.8) (Anderson, 2010; Bayios et al., 2006; Santos et al., 2014).

But, our VB student-athletes are shorter than some recently observed heights of American NCAA and elite/Olympic level VB athletes from around the world (See Table 5.1) (Carbuhn et al., 2010; Ćopić, Dopsaj, Ivanović, Nešić, \& Jarić, 2014; Fernández, Rubiano, \& Hoyos, 2017; Maddalozzo et al., 2002; Martín-Matillas et al., 2014; Nikolaidis, Ziv, Arnon, \& Lidor, 2012; Stanforth et al., 2014). The WSOC student-athletes were taller than recently observed NCAA female soccer student-athletes and national-level female soccer players (Arena et al., 2017; Ballard et al., 2004; Brännström et al., 2017; Datson et al., 2014; Esco et al., 2015; Ferry et al., 2011; Minett, Binkley, Weidauer, \& Specker, 2017; Randers et al., 2013; Stanforth et al., 2014).

\subsection{Fat Mass}

It has been acknowledged and reported that athletes in general will have lower percentage of FM than non-athletic counterpart (Malina, 2007; Santos et al., 2014). However, not all sports share this outcome or hold this standard due to differences in specific requirements for specific sports. In our study, we note that gender accounted for the pattern of differences in relative amounts of FM and FFM. In other words, while sport-specific training and conditioning 
influences the amount of FM, FFM, and BMD, the distribution of FM can be accounted for by gender (see Table 2.4).

We measured percentage of $\mathrm{FM}(\% \mathrm{BF}, \% \mathrm{BF}=$ total fat mass $\div$ total mass $)$ in the athletes to compare the teams in our study and to compare to other studies. In our study, BSB studentathletes were leaner (18.7\%) when compared to other studies (20.4\%, Loenneke et al. (2013) and 22.2\%, Oates and Oates (2009); Oates et al. (2009)) that used DXA as a BC method. In a different study, Rossi et al. (2017) observed that their BSB players weighed less and had less body fat $(\sim 13.0 \%)$ as compared to our study $(18.7 \%)$. This data cannot be directly compared to our study since their heights were not presented in the paper, as one cannot discern whether the athlete is under or over-weight for his body size. Rossi et al. (2017) also used ADP and not DXA, therefore our results are not comparable to Rossi's since there are inherent differences in the method of assessment. VB student-athletes were had higher \%BF (27.8\%) in this study compared to other studies that used DXA (see Table 2.8) (Ćopić et al., 2014; Fernández et al., 2017; Martín-Matillas et al., 2014; Mielgo-Ayuso, Zourdos, Calleja-González, Urdampilleta, \& Ostojic, 2015; Nikolaidis et al., 2012; Santos et al., 2014; Stanforth et al., 2014). WSOC was observed to have higher \% BF (25\%) when compared to other studies as well (Brännström et al., 2017; Esco et al., 2015; Ferry et al., 2011; Johnson, 2016; Minett et al., 2017; Reed et al., 2013; Stanforth et al., 2014).

In regard to collegiate basketball student-athletes, we have not yet found other studies that specifically looked at 18 and older collegiate or professional basketball players using DXA as a method. However, when comparing with Portuguese 16 - 18 year-old basketball players, the student-athletes in this study had similar \%BF amounts ( 15\% \%BF) (Santos et al., 2014). When comparing with prior studies conducted in the 1990s or with NBA professionals (see 
Table 2.5), the MBB student-athletes in this study had more FM in comparison (Bolonchuk et al., 1991; Gonzalez et al., 2013; Latin et al., 1994; Tavino, Bowers, \& Archer, 1995).

However, once again this comparison is difficult because methods other than DXA were used. The unfavorable or not optimal amounts of FM in most of the student-athletes in our population may be explained by factors that were not controlled but have strong influences such as strength training, nutrition, health, and environmental stressors. In the observations of overthe-season changes in $\mathrm{BC}$, there were marginal differences from pre-season to end-season scans. For MBB and $\mathrm{BSB}$, there was a reduction in FM but not of significance, especially as the student-athletes were able to gain FFM and VAT.

\subsection{Visceral Adipose Tissue}

Recent studies have shown that it is important to understand VAT since it is not only associated with the relative and absolute amounts of FM, but is also influenced by the amount of psychological stress on the individual which is a risk factor of metabolic disease (Bosch et al., 2014; Mittendorfer, 2011). In this study, a small correlation was observed wherein VAT amounts increased with body height but when calculating for cardiometabolic risk using VAT, the area is significantly smaller than the lowest quintile value for risk (Kaess et al., 2012; Miazgowski et al., 2017). For example, with many cardiometabolic factors, VAT follows a sex pattern as seen in our study that males had significantly higher VAT than females; but we noted differences between the individual male sports, as well. It was observed that there was no VAT present in some of the female athletes while all male athletes had VAT present. Other authors have observed a pattern no measured VAT amongst female athletes, as well (Jennewine, 2015; Taylor et al., 2010). Current literature and review suggested that high levels of aerobic exercise utilizes 
triglycerides and non-esterified fatty acids from VAT over lipids from subcutaneous adipose tissue (Ibrahim, 2010; Thompson, Karpe, Lafontan, \& Frayn, 2012). This leaves the question to why some sports that have a higher aerobic workload like MBB, have higher VAT amounts than sedentary sports.

With that said, the perception that athletes are generally healthy is based on cardiorespiratory fitness and exercise capacity (Bayios et al., 2006; Bosch et al., 2015b; Lee et al., 1999). Alternative factors like VAT, FMI, and FFMI, could be markers or indicator of health in this population but additional studies are required and warranted.

\subsection{FMI and FFMI}

Measuring FM and FFM is highly dependent on the availability of the method to measure BC. In studies that do FMI in athletes, the observers use SKF to assess FM while studies that address FMI in non-athletic and disease states use more precise tools to measure FM. In Europe, standard of practice for BC, especially for sports, has been using an accredited anthropometrist (ISAK Level 2) to perform SKF measurements (Iga, Scott, George, \& Drust, 2014). DXA software can calculate FM index and FFM Index (also known as Body Fat Mass Index and Lean Body Mass Index, respectively), and in this study these values were manually calculated.

Observations in FFMI showed that trends were suggested between genders, and when compared to other studies this study indicated higher values in FFMI (Santos et al., 2014). When compared to a larger population, of 18 - 34 year old non-athletes, the MBB and BSB student-athletes were observed to be in the $95^{\text {th }}$ and $90^{\text {th }}$ percentile, respectively, while the women's sports are in the $75^{\text {th }}$ percentile (Schutz, Kyle, \& Pichard, 2002). FMI showed varied results that were parallel to FM values reported previously. When comparing FMI values to a large population of 18 -34 
year old, MBB was at the $50^{\text {th }}$ percentile, WSOC was $70^{\text {th }}$ percentile and BSB and VB were both at the $75^{\text {th }}$ percentile (Schutz et al., 2002). FMI has also been associated and reported to be a risk factor for cardiometabolic diseases. When comparing the FMI results, the VB student-athletes may be at a higher risk (a 15\% increase) for metabolic syndrome compared to the general population (Liu, Ma, Lou, \& Liu, 2013). In the literature, current use of FMI and FFMI has been directed towards recognizing catabolic states or malnutrition (VanItallie, Yang, Heymsfield, Funk, \& Boileau, 1990). Investigation into the utility of FMI and FFMI values could have better sensitivity to an athletic population when addressing weight management, female athlete triad, and other disease states.

\subsection{BMD}

Before the use of DXA, FFM included bone mineral and this presented a potential source of error because bone metabolism can be affected by various mechanical stressors, vitamin D levels, health, ethnicities, and nutrition of athlete. Therefore, the inability to quantify bone separately from lean mass created a larger discrepancy in previous 2-compartment model methods (BIA, SKF, Densitometry). DXA allows the direct measurement of bone, which has been shown to vary in athletes of different sports (Oates \& Oates, 2009). In this study, all of the student-athletes that participated had higher BMD values when compared to BMD means from other reported studies. In this study, it was observed that all sports had fairly high Z-scores (mean $\geq 2.4$ ), with WSOC having the lowest average of 2.4. It was also observed that the courtbased sports had higher BMD values than the field-based sports although this did not reach significance. It is generally understood that mechanical stressors from ground reaction forces can increase BMD, which can explain the trend observed with MBB and VB having higher values 
than BSB and WSOC (Martin, 2015). When comparing to other sources, WSOC had higher values than northern European counterparts by a full 1.0 (see Table 5.2) (Brännström et al., 2017; Ferry et al., 2011). There were few reported values for BMD in BSB players. One study reported lower BMD than the players in our study (2.5 vs 1.3, Z-score) (Oates \& Oates, 2009; Oates et al., 2009). Fewer studies have observed BMD values in male basketball players, but from the few that have been reported, MBB student athletes in our study had higher relative values (2.9 Z-score) in comparison to another study (1.03, Z-score) (Santos et al., 2014). A possible reason for the larger discrepancies between these groups could be due to the higher vitamin D status from higher amounts of UV exposure in California. Other factors include higher intake of dairy products and strength training programs. Interestingly, when comparing pre- and end-of season BMD values in male sports, it was observed that BMD increased over the season in both sports. Increased time with sports-specific training, strength training, and modest increase in FFM could explain this finding.

It is important to measure BMD in women, since this population can be highly susceptible to osteoporosis, body dysmorphia, and other weight-related issues. Accruing bone mineral and increasing bone mass is important for everyone. Women need to be more proactive in establishing high bone mass during the adolescent period as peak calcium absorption and BMD occurs in a women's late-teens/early-twenties (Bemben, Buchanan, Bemben, \& Knehans, 2004; Creighton, Morgan, Boardley, \& Brolinson, 2001; Ferry et al., 2011). After these years, maintenance is a key to keeping a high BMD. To achieve a high BMD, mechanical stressors from movement, impact, and ground reaction forces, like in sports such as soccer and volleyball, help increase BMD by remodeling bones to withstand these stressors (Bemben et al., 2004; Creighton et al., 2001; Recker et al., 1992). It has been shown that women who participate in 
physical activity have higher BMD (Andreoli et al., 2001; Carbuhn et al., 2010; Ferry et al., 2011; Minett et al., 2017; Recker et al., 1992). This BMD remains high if continued activity occurs through middle age and post-menopause (Creighton et al., 2001; Ito et al., 2001; Minett et al., 2017) . For the health of the female athlete, other disease states may be of more concern such as the female athlete triad syndrome, amenorrhea, sports induced anemia, anemia, and others (Bemben et al., 2004; Carbuhn et al., 2010; Creighton et al., 2001; Minett et al., 2017; Recker et al., 1992). Retaining FFM helps retain BMD, but low weight in general has been shown to cause some of these disease states while allowing susceptibility to low BMD (Bemben et al., 2004;

Carbuhn et al., 2010; Datson et al., 2014; Santos et al., 2014). Utilizing DXA as a screening tool can provide extra information to prevent possible adverse situations (Santos et al., 2014). 


\section{Summary/Conclusion}

The present study was performed to assess the $\mathrm{BC}$ values of collegiate athletes using DXA and compare the differences between various American collegiate sports. Pre-season scans of athletes in the sports: $\mathrm{MBB}, \mathrm{BSB}, \mathrm{VB}$, and WSOC, were used to establish a baseline value and compare athletes who trained in their specific sport. Additional scans were performed in MBB and BSB at the end of their respective season, to observe if the stressors of a competitive season alter BC. Primary DXA outcomes were to measure FM, FFM, BMD, and VAT. This study is the first to present VAT of the collegiate athletic population.

Differences in sports showed a strong correlation between frame size (height) and FFM. This is apparent between MBB and BSB as there is a significant difference in height and FFM (p $<0.0001)$. After normalizing for height, FFM was seen to be correlated with sex than to a specific sport, which was further elucidated by the fat free mass index (FFMI). FFMI showed a

clear division between sexes where men had larger FFMI $\left(21.0 \mathrm{~kg} / \mathrm{m}^{2}\right)$ than women $\left(16.7 \mathrm{~kg} / \mathrm{m}^{2}\right)$. Body adiposity varied with sex and sport as well. Higher FM values relative to total body weight (\%BF) was observed in female athletes than males (27.8\% VB and 25\% WSOC vs. $18.7 \%$ BSB and $14.8 \% \mathrm{MBB})$. Yet we did see that some of the male and female shared the similar amounts of FM (35.0 lb WSOC and $36.1 \mathrm{lb} \mathrm{BSB).} \mathrm{While} \mathrm{FM} \mathrm{showed} \mathrm{differences} \mathrm{between} \mathrm{sport,} \mathrm{FMI}$ showed larger differences between sexes. FMI may be a more powerful tool to use than $\% \mathrm{BF}$ as this value may be a better representation of necessary FM and non-optimal amounts of FM.

Differences in FM were also observed when dividing the athletic populations by sport type (e.g. power vs endurance) where power-based sports had higher \%BF than endurance types. A similar trend should have been observed with VAT but was observed to be the opposite. It was noted that the higher FFM values correlated with the larger the VAT values. Within VAT, the 
sex explained majority of the differences, as higher percentages of non-existent values (0.00 lbs. of VAT) are noted in female athletes than males.

The results of our study would serve the purpose of assisting the coaches and training staff to design training and nutritional programs for collegiate student-athletes. In addition, this could provide interesting comparisons to the sedentary populations as a way of examining additional benefits of exercise. Based on the findings of this study, health professional should be encouraged to obtain FMI values instead of BMI values for clinical or epidemiological studies in athletic populations, because FMI values show more accurate correlations with health riskfactors in non-athletic populations. This study also provides a foundation for VAT values in various collegiate athletic populations and proposes that measuring VAT will be useful in determining nutritional and training programs for athletes and non-athletes.

\subsection{Future Considerations}

This thesis presents the analyses of a select set of data pertaining to $\mathrm{BC}$ extracted from the DXA's output generated by the EnCORE software. Other fields of the DXA output include: appendicular lean soft tissue mass, lean mass, android, and gynoid values. Along with femoral neck and lumbar spine scans, these data can help investigate topics such as:

- Measuring skeletal tissue mass (Kim et al., 2004; Kim et al., 2002)

- Observation of nutritional and training interventions on body segmental inertial parameters (Arena et al., 2017)

Additionally, while the study addresses various sports and genders, there are other issues that should be addressed:

- Observation and comparison of all NCAA sports and of genders 
- Investigate the lack of VAT in female athletes by including more sports and training experiences

- Establishing reference level of FMI and FFMI values for all sports

- Randomized control dietary intervention in the sports analyzed in this study and other sports that have both genders

- Interventional studies or observational studies over the season (Minett et al., 2017; Stanforth et al., 2014)

Other investigations can include performance data to create correlations and investigate into causations of changes in certain tissues like FFM, BMD, and VAT. These analyses should be conducted for all sports.

Current literature presents more research regarding women's sports than men's sports. These studies could help investigate gender differences in accumulation or absence of accumulation of tissues, as seen in this study where women had no VAT. Finally, further investigations into measuring blood lipid panels, hormones, and circulating cytokines may provide a mechanism by which accumulation of certain tissues occurs and if there is a threshold value that can be avoided. 


\section{References}

Abraham, T. M., Pedley, A., Massaro, J. M., Hoffmann, U., \& Fox, C. S. (2015). Association Between Visceral and Subcutaneous Adipose Depots and Incident Cardiovascular Disease Risk Factors. Circulation, 132(17), 1639-1647. doi:10.1161/circulationaha.114.015000

Alfrey, A. C., \& Miller, N. L. (1973). Bone Magnesium Pools in Uremia. J Clin Invest, 52(12), 3019-3027.

Anderson, D. E. (2010). The impact of feedback on dietary intake and body composition of college women volleyball players over a competitive season. The Journal of Strength \& Conditioning Research, 24(8), 2220-2226.

Andreoli, A., Monteleone, M., Van Loan, M., Promenzio, L., Tarantino, U., \& De Lorenzo, A. (2001). Effects of different sports on bone density and muscle mass in highly trained athletes. Medicine \& Science in Sports \& Exercise, 33(4), 507-511.

Arem, H., Moore, S. C., Patel, A., Hartge, P., De Gonzalez, A. B., Visvanathan, K., . . Adami, H. O. (2015). Leisure time physical activity and mortality: a detailed pooled analysis of the dose-response relationship. JAMA internal medicine, 175(6), 959-967.

Arena, S. L., McLaughlin, K., Nguyen, A.-D., Smoliga, J. M., \& Ford, K. R. (2017). A Comparison of Body Segment Inertial Parameter Estimation Methods and Joint Moment and Power Calculations During a Drop Vertical Jump in Collegiate Female Soccer Players. Journal of applied biomechanics, 33(1), 76-79.

Ballard, T. P., Fafara, L., \& Vukovich, M. D. (2004). Comparison of Bod Pod and DXA in female collegiate athletes. Medicine and science in sports and exercise, 36(4), 731-735.

Bayios, I. A., Bergeles, N. K., Apostolidis, N. G., Noutsos, K. S., \& Koskolou, M. D. (2006). Anthropometric, body composition and somatotype differences of Greek elite female basketball, volleyball and handball players. Journal of sports medicine and physical fitness, 46(2), 271.

Bemben, D. A., Buchanan, T. D., Bemben, M. G., \& Knehans, A. W. (2004). Influence of type of mechanical loading, menstrual status, and training season on bone density in young women athletes. Journal of strength and Conditioning Research, 18(2), 220-226.

Bidulescu, A., Liu, J., Hickson, D. A., Hairston, K. G., Fox, E. R., Arnett, D. K., . . Gibbons, G. H. (2013). Gender differences in the association of visceral and subcutaneous adiposity with adiponectin in African Americans: the Jackson Heart Study. BMC Cardiovasc Disord, 13(1), 9.

Blaak, E. (2001). Gender differences in fat metabolism. Current Opinion in Clinical Nutrition \& Metabolic Care, 4(6), 499-502.

Bolonchuk, W. W., Lukaski, H. C., \& Siders, W. A. (1991). Main content area The structural, functional, and nutritional adaptation of college basketball players over a season. Journal of sports medicine and physical fitness, 31(2), 165-172.

Bosch, T. A., Burruss, T. P., Weir, N. L., Fielding, K. A., Engel, B. E., Weston, T. D., \& Dengel, D. R. (2014). Abdominal body composition differences in NFL football players. $J$ Strength Cond Res, 28(12), 3313-3319. doi:10.1519/JSC.0000000000000650

Bosch, T. A., Chow, L., Dengel, D. R., Melhorn, S. J., Webb, M., Yancey, D., . . Schur, E. A. (2015a). In adult twins, visceral fat accumulation depends more on exceeding sex- 
specific adiposity thresholds than on genetics. Metabolism-Clinical and Experimental, 64(9), 991-998.

Bosch, T. A., Dengel, D. R., Ryder, J. R., Kelly, A. S., \& Chow, L. (2015b). Fitness Level is Associated with Sex-Specific Regional Fat Differences in Normal Weight Young Adults. Journal of endocrinology and diabetes, 2(2).

Brännström, A., Yu, J.-G., Jonsson, P., Åkerfeldt, T., Stridsberg, M., \& Svensson, M. (2017). Vitamin D in relation to bone health and muscle function in young female soccer players. European journal of sport science, 17(2), 249-256.

Brožek, J., Grande, F., Anderson, J. T., \& Keys, A. (1963). DENSITOMETRIC ANALYSIS OF BODY COMPOSITION: REVISION OF SOME QUANTITATIVE ASSUMPTIONS*. Annals of the New York Academy of Sciences, 110(1), 113-140. doi:10.1111/j.17496632.1963.tb17079.x

Carbuhn, A. F., Fernandez, T. E., Bragg, A. F., Green, J. S., \& Crouse, S. F. (2010). Sport and training influence bone and body composition in women collegiate athletes. The Journal of Strength \& Conditioning Research, 24(7), 1710-1717.

Caspersen, C. J., Powell, K. E., \& Christenson, G. M. (1985). Physical activity, exercise, and physical fitness: definitions and distinctions for health-related research. Public health reports, $100(2), 126$.

Castiglioni, S., Cazzaniga, A., Albisetti, W., \& Maier, J. A. M. (2013). Magnesium and Osteoporosis: Current State of Knowledge and Future Research Directions. Nutrients, 5(8), 3022-3033. doi:10.3390/nu5083022

Ćopić, N., Dopsaj, M., Ivanović, J., Nešić, G., \& Jarić, S. (2014). Body composition and muscle strength predictors of jumping performance: differences between elite female volleyball competitors and nontrained individuals. The Journal of Strength \& Conditioning Research, 28(10), 2709-2716.

Cote, K. D., \& Adams, W. C. (1993). Effect of bone density on body composition estimates in young adult black and white women. Med Sci Sports Exerc, 25(2), 290-296.

Creighton, D. L., Morgan, A. L., Boardley, D., \& Brolinson, P. G. (2001). Weight-bearing exercise and markers of bone turnover in female athletes. Journal of Applied Physiology, 90(2), 565-570.

Datson, N., Hulton, A., Andersson, H., Lewis, T., Weston, M., Drust, B., \& Gregson, W. (2014). Applied physiology of female soccer: an update. Sports Medicine, 44(9), 1225-1240.

Drinkwater, E. J., Pyne, D. B., \& McKenna, M. J. (2008). Design and interpretation of anthropometric and fitness testing of basketball players. Sports Medicine, 38(7), 565-578.

Dupertuis, C. W., Pitts, G. C., Osserman, E. F., Welham, W. C., \& Behnke, A. R. (1951). Relation of specific gravity to body build in a group of healthy men. J Appl Physiol, 3(11), 676-680.

Eknoyan, G. (2008). Adolphe Quetelet (1796-1874)--the average man and indices of obesity. Nephrol Dial Transplant, 23(1), 47-51. doi:10.1093/ndt/gfm517

Ellis, K. J. (2000). Human body composition: in vivo methods. Physiol Rev, 80(2), 649-680. doi:10.1152/physrev.2000.80.2.649

Enzi, G., Gasparo, M., Biondetti, P. R., Fiore, D., Semisa, M., \& Zurlo, F. (1986). Subcutaneous and visceral fat distribution according to sex, age, and overweight, evaluated by computed tomography. The American journal of clinical nutrition, 44(6), 739-746. 
Esco, M. R., Snarr, R. L., Leatherwood, M. D., Chamberlain, N. A., Redding, M. L., Flatt, A. A., ... Williford, H. N. (2015). Comparison of total and segmental body composition using DXA and multifrequency bioimpedance in collegiate female athletes. The Journal of Strength \& Conditioning Research, 29(4), 918-925.

Fernández, J., Rubiano, P., \& Hoyos, L. (2017). MORPHOLOGICAL PROFILE OF ELITE WOMEN VOLLEYBALL PLAYERS. REVIEW ARTICLE. Revista Internacional de Medicina y Ciencias de la Actividad Física y del Deporte, 17(68).

Ferry, B., Duclos, M., Burt, L., Therre, P., Le Gall, F., Jaffré, C., \& Courteix, D. (2011). Bone geometry and strength adaptations to physical constraints inherent in different sports: comparison between elite female soccer players and swimmers. Journal of bone and mineral metabolism, 29(3), 342-351.

Flegal, K. M., Kit, B. K., Orpana, H., \& Graubard, B. I. (2013). Association of all-cause mortality with overweight and obesity using standard body mass index categories: a systematic review and meta-analysis. JAMA, 309(1), 71-82.

Frontera, W. R., \& Ochala, J. (2015). Skeletal muscle: a brief review of structure and function. Calcified tissue international, 96(3), 183-195.

Gallagher, D., Belmonte, D., Deurenberg, P., Wang, Z., Krasnow, N., Pi-Sunyer, F. X., \& Heymsfield, S. B. (1998). Organ-tissue mass measurement allows modeling of REE and metabolically active tissue mass. American Journal of Physiology-Endocrinology and Metabolism, 275(2), E249-E258.

Gonzalez, A. M., Hoffman, J. R., Rogowski, J. P., Burgos, W., Manalo, E., Weise, K., ... Stout, J. R. (2013). Performance changes in NBA basketball players vary in starters vs. nonstarters over a competitive season. The Journal of Strength \& Conditioning Research, 27(3), 611-615.

Healthcare, G. (2017). Lunar iDXA: The Intelligent DXA: GEHealthcare.

Heymsfield, S. (2005). Human body composition (2nd ed.). Champaign, IL: Human Kinetics.

Heymsfield, S. B., Adamek, M., Gonzalez, M. C., Jia, G., \& Thomas, D. M. (2014). Assessing skeletal muscle mass: historical overview and state of the art. Journal of cachexia, sarcopenia and muscle, 5(1), 9-18.

Heymsfield, S. B., Ebbeling, C. B., Zheng, J., Pietrobelli, A., Strauss, B. J., Silva, A. M., \& Ludwig, D. S. (2015). Multi-component molecular-level body composition reference methods: evolving concepts and future directions. Obes Rev, 16(4), 282-294. doi:10.1111/obr.12261

Heymsfield, S. B., Wang, Z., Baumgartner, R. N., Dilmanian, F. A., Ma, R., \& Yasumura, S. (1993). Body composition and aging: a study by in vivo neutron activation analysis. $J$ Nutr, 123(2 Suppl), 432-437.

Heyward, V. H., \& Gibson, A. (2014). Advanced fitness assessment and exercise prescription 7th edition: Human kinetics.

Heyward, V. H., \& Wagner, D. R. (2004). Applied body composition assessment (2nd ed.). Champaign, IL: Human Kinetics.

Hoffman, J. R., Fry, A. C., Howard, R., Maresh, C. M., \& Kraemer, W. J. (1991). Strength, Speed and Endurance Changes During the Course of a Division I Basketball Season. The Journal of Strength \& Conditioning Research, 5(3), 144-149. 
Houtkooper, L. B., Lohman, T. G., Going, S. B., \& Howell, W. H. (1996). Why bioelectrical impedance analysis should be used for estimating adiposity. The American journal of clinical nutrition, 64(3), 436S-448S.

Hunter, G. R., Hilyer, J., \& Forster, M. A. (1993). Changes in Fitness During 4 Years of Intercollegiate Basketball. The Journal of Strength \& Conditioning Research, 7(1), 2629.

Ibrahim, M. M. (2010). Subcutaneous and visceral adipose tissue: structural and functional differences. Obesity reviews, 11(1), 11-18.

Iga, J., Scott, M., George, K., \& Drust, B. (2014). Seasonal changes in multiple indices of body composition in professional football players. International journal of sports medicine, 35(12), 994-998.

International Society for Clinical Densitometry. (2017, April 20 - 22, 2017). DXA Technology for Total and Regional Body Composition Measures. Paper presented at the ISCD Body Composition Course, Orlando, FL.

Ito, M., Nakamura, T., Ikeda, S., Tahara, Y., Hashmi, R., Tsurusaki, K., . . Hayashi, K. (2001). Effects of lifetime volleyball exercise on bone mineral densities in lumbar spine, calcaneus and tibia for pre-, peri-and postmenopausal women. Osteoporosis international, 12(2), 104-111.

Jackson, A. S., \& Pollock, M. L. (1978). Generalized equations for predicting body density of men. Br J Nutr, 40(3), 497-504.

Jackson, A. S., \& Pollock, M. L. (1984). Research progress in validation of clinical methods of assessing body composition. Med Sci Sports Exerc, 16(6), 606 - 613.

Jackson, A. S., \& Pollock, M. L. (1985). Practical assessment of body composition. The Physician and sportsmedicine, 13(5), 76-90.

Jahnen-Dechent, W., \& Ketteler, M. (2012). Magnesium basics. Clin Kidney J, 5(Suppl 1), i3i14. doi:10.1093/ndtplus/sfr163

Jennewine, J. M. (2015). Interrelationship of Diet, Visceral Adipose Tissue and Cortisol in Premenopausal Female Runners. The Ohio State University.

Johnson, J. T. (2016). Preseason Versus Postseason Body Composition Analysis in Women's Soccer. Research Quarterly for Exercise and Sport, 87(S2), A98.

Kaess, B., Pedley, A., Massaro, J., Murabito, J., Hoffmann, U., \& Fox, C. (2012). The ratio of visceral to subcutaneous fat, a metric of body fat distribution, is a unique correlate of cardiometabolic risk. Diabetologia, 55(10), 2622-2630.

Karstoft, K., \& Pedersen, B. K. (2016). Exercise and type 2 diabetes: focus on metabolism and inflammation. Immunology and cell biology, 94(2), 146-150.

Kaul, S., Rothney, M. P., Peters, D. M., Wacker, W. K., Davis, C. E., Shapiro, M. D., \& Ergun, D. L. (2012). Dual-energy X-ray absorptiometry for quantification of visceral fat. Obesity, 20(6), 1313-1318.

Kim, J., Heshka, S., Gallagher, D., Kotler, D. P., Mayer, L., Albu, J., . . Heymsfield, S. B. (2004). Intermuscular adipose tissue-free skeletal muscle mass: estimation by dualenergy X-ray absorptiometry in adults. Journal of Applied Physiology, 97(2), 655-660.

Kim, J., Wang, Z., Heymsfield, S. B., Baumgartner, R. N., \& Gallagher, D. (2002). Total-body skeletal muscle mass: estimation by a new dual-energy X-ray absorptiometry method. The American journal of clinical nutrition, 76(2), 378-383. 
Kopelman, P. (2007). Health risks associated with overweight and obesity. Obesity reviews, 8(s1), 13-17.

Koster, A., Ding, J., Stenholm, S., Caserotti, P., Houston, D. K., Nicklas, B. J., . . Newman, A. B. (2011). Does the amount of fat mass predict age-related loss of lean mass, muscle strength, and muscle quality in older adults? Journals of Gerontology Series A:

Biomedical Sciences and Medical Sciences, 66(8), 888-895.

Latin, R. W., Berg, K., \& Baechle, T. (1994). Physical and Performance Characteristics of NCAA Division I Male Basketball Players. The Journal of Strength \& Conditioning Research, 8(4), 214-218.

Lee, C. D., Blair, S. N., \& Jackson, A. S. (1999). Cardiorespiratory fitness, body composition, and all-cause and cardiovascular disease mortality in men. Am J Clin Nutr, 69(3), 373380.

Lee, I.-M., Hsieh, C.-c., \& Paffenbarger, R. S. (1995). Exercise intensity and longevity in men: the Harvard Alumni Health Study. JAMA, 273(15), 1179-1184.

Lee, S. Y., \& Gallagher, D. (2008). Assessment methods in human body composition. Current opinion in clinical nutrition and metabolic care, 11(5), 566.

Liu, P., Ma, F., Lou, H., \& Liu, Y. (2013). The utility of fat mass index vs. body mass index and percentage of body fat in the screening of metabolic syndrome. BMC Public Health, $13(1), 629$.

Loenneke, J. P., Wray, M. E., Wilson, J. M., Barnes, J. T., Kearney, M. L., \& Pujol, T. J. (2013). Accuracy of field methods in assessing body fat in collegiate baseball players. Research in Sports Medicine, 21(3), 286-291.

Lohman, T. G., \& Chen, Z. (2005). Dual-Energy X-Ray Absorptiometry. In S. B. Heymsfield, T. G. Lohman, Z. Wang, \& S. B. Going (Eds.), Human Body Composition (2nd ed., pp. 63 77). Chicago, IL: Human Kinetics.

Lohman, T. G., Houtkooper, L., \& Going, S. B. (1997). Body Fat Measurement Goes HighTech: Not All Are Created Equal. ACSM's Health \& Fitness Journal, 1(1), 30-35.

Maddalozzo, G. F., Cardinal, B. J., \& Snow, C. M. (2002). Concurrent validity of the BOD POD and dual energy $\mathrm{x}$-ray absorptiometry techniques for assessing body composition in young women. Journal of the American Dietetic Association, 102(11), 1677-1679.

Malina, R. M. (2007). Body composition in athletes: assessment and estimated fatness. Clinics in sports medicine, 26(1), 37-68.

Martin, A. D., \& Drinkwater, D. T. (1991a). Variability in the measures of body fat. Sports Medicine, 11(5), 277-288.

Martin, A. D., \& Drinkwater, D. T. (1991b). Variability in the measures of body fat. Assumptions or technique? Sports Med, 11(5), 277-288.

Martin, R. B. (2015). Skeletal tissue mechanics (Second edition.. ed.): New York, NY : Springer.

Martín-Matillas, M., Valadés, D., Hernández-Hernández, E., Olea-Serrano, F., Sjöström, M., Delgado-FERNáNDEZ, M., \& Ortega, F. B. (2014). Anthropometric, body composition and somatotype characteristics of elite female volleyball players from the highest Spanish league. Journal of sports sciences, 32(2), 137-148.

Merriam-Webster. (2018, March 24, 2018). “Athlete.”. Retrieved from www.merriamwebster.com/dictionary/athlete.

Miazgowski, T., Kucharski, R., Sołtysiak, M., Taszarek, A., Miazgowski, B., \& Widecka, K. (2017). Visceral fat reference values derived from healthy European men and women 
aged 20-30 years using GE Healthcare dual-energy x-ray absorptiometry. PloS one, 12(7), e0180614.

Mielgo-Ayuso, J., Zourdos, M. C., Calleja-González, J., Urdampilleta, A., \& Ostojic, S. M. (2015). Dietary intake habits and controlled training on body composition and strength in elite female volleyball players during the season. Applied Physiology, Nutrition, and Metabolism, 40(8), 827-834.

Minett, M. M., Binkley, T. B., Weidauer, L. A., \& Specker, B. L. (2017). Changes in body composition and bone of female collegiate soccer players through the competitive season and off-season. Journal of musculoskeletal \& neuronal interactions, 17(1), 386.

Mitchell, H., Hamilton, T., Steggerda, F., \& Bean, H. (1945). The chemical composition of the adult human body and its bearing on the biochemistry of growth. Journal of Biological Chemistry, 158(3), 625-637.

Mittendorfer, B. (2011). Origins of metabolic complications in obesity: adipose tissue and free fatty acid trafficking. Current opinion in clinical nutrition and metabolic care, 14(6), 535.

Moon, J. (2013). Body composition in athletes and sports nutrition: an examination of the bioimpedance analysis technique. Eur J Clin Nutr, 67(S1), S54.

National Heart, L., \& Institute, B. (1998). Clinical guidelines on the identification, evaluation, and treatment of overweight and obesity in adults: executive summary. Am J Clin Nutr, 68, 899-917.

Nikolaidis, P. T., Ziv, G., Arnon, M., \& Lidor, R. (2012). Physical characteristics and physiological attributes of female volleyball players - the need for individual data. The Journal of Strength \& Conditioning Research, 26(9), 2547-2557.

Oates, M. (2017). Methods Other Than DXA for Body Composition Testing. ISCD Body Composition Course. Lecture.

Oates, M., \& Oates, D. (2009). Body Composition of Collegiate Swimmers, Runners, and Baseball Players Measured with iDXA. Paper presented at the Society for Bone and Mineral Research (ASBMR), Denver, Colorado, USA. Abstract retrieved from

Oates, M., Oates, D., \& Barden, H. (2009). Body Composition of Collegiate Swimmers and Baseball Players Measured with iDXA. Journal of Clinical Densitometry, 12(3), 402.

Ogden, C. L., Carroll, M. D., Curtin, L. R., McDowell, M. A., Tabak, C. J., \& Flegal, K. M. (2006). Prevalence of overweight and obesity in the United States, 1999-2004. JAMA, 295(13), 1549-1555.

Ogden, C. L., Carroll, M. D., Kit, B. K., \& Flegal, K. M. (2014). Prevalence of childhood and adult obesity in the United States, 2011-2012. JAMA, 311(8), 806-814.

Ostojic, S. M., Mazic, S., \& Dikic, N. (2006). Profiling in basketball: Physical and physiological characteristics of elite players. Journal of strength and Conditioning Research, 20(4), 740 .

Paffenbarger Jr, R. S., Hyde, R., Wing, A. L., \& Hsieh, C.-c. (1986). Physical activity, all-cause mortality, and longevity of college alumni. New England journal of medicine, 314(10), 605-613.

Penn, I., Wang, Z., Buhl, K. M., Allison, D. B., Burastero, S. E., \& Heymsfield, S. B. (1994). Body composition and two-compartment model assumptions in male long distance runners. Medicine and science in sports and exercise, 26(3), 392-397. 
Pietrobelli, A., Heymsfield, S. B., Wang, Z. M., \& Gallagher, D. (2001). Multi-component body composition models: recent advances and future directions. Eur J Clin Nutr, 55(2), 69-75.

Ponce-González, J. G., Olmedillas, H., Calleja-González, J., Guerra, B., \& Sanchis-Moysi, J. (2015). Physical fitness, adiposity and testosterone concentrations are associated to playing position in professional basketballers. Nutricion hospitalaria, 31(6).

Prado, C. M., \& Heymsfield, S. B. (2014). Lean tissue imaging: a new era for nutritional assessment and intervention. JPEN J Parenter Enteral Nutr, 38(8), 940-953. doi:10.1177/0148607114550189

Randers, M. B., Andersen, L. J., Orntoft, C., Bendiksen, M., Johansen, L., Horton, J., . . . Krustrup, P. (2013). Cardiovascular health profile of elite female football players compared to untrained controls before and after short-term football training. Journal of sports sciences, 31(13), 1421-1431.

Recker, R. R., Davies, K. M., Hinders, S. M., Heaney, R. P., Stegman, M. R., \& Kimmel, D. B. (1992). Bone gain in young adult women. JAMA, 268(17), 2403-2408.

Reed, J. L., De Souza, M. J., \& Williams, N. I. (2013). Changes in energy availability across the season in Division I female soccer players. Journal of sports sciences, 31(3), 314-324.

Rossi, F. E., Landreth, A., Beam, S., Jones, T., Norton, L., \& Cholewa, J. M. (2017). The effects of a sports nutrition education intervention on nutritional status, sport nutrition knowledge, body composition, and performance during off season training in NCAA Division I baseball players. Journal of sports science \& medicine, 16(1), 60.

Ryu, M., Jo, J., Lee, Y., Chung, Y.-S., Kim, K.-M., \& Baek, W.-C. (2013). Association of physical activity with sarcopenia and sarcopenic obesity in community-dwelling older adults: the Fourth Korea National Health and Nutrition Examination Survey. Age and ageing, 42(6), 734-740.

Santos, D. A., Dawson, J. A., Matias, C. N., Rocha, P. M., Minderico, C. S., Allison, D. B., . . Silva, A. M. (2014). Reference values for body composition and anthropometric measurements in athletes. PloS one, 9(5), e97846.

Schutz, Y., Kyle, U., \& Pichard, C. (2002). Fat-free mass index and fat mass index percentiles in Caucasians aged 18-98 y. International journal of obesity, 26(7), 953.

Sherwood, L. (2015). Human physiology: from cells to systems: Cengage learning.

Sonksen, P. (2016). Determination and regulation of body composition in elite athletes. $\mathrm{Br} J$ Sports Med, bjsports-2016-096742.

Spaniol, F. J. (2009). Baseball athletic test: A baseball-specific test battery. Strength \& Conditioning Journal, 31(2), 26-29.

Stanforth, P. R., Crim, B. N., Stanforth, D., \& Stults-Kolehmainen, M. A. (2014). Body composition changes among female NCAA division 1 athletes across the competitive season and over a multiyear time frame. The Journal of Strength \& Conditioning Research, 28(2), 300-307.

Tavino, L. P., Bowers, C. J., \& Archer, C. B. (1995). Effects of Basketball on Aerobic Capacity, Anaerobic Capacity, and Body Composition of Male College Players. The Journal of Strength \& Conditioning Research, 9(2), 75-77.

Taylor, A. E., Ebrahim, S., Ben-Shlomo, Y., Martin, R. M., Whincup, P. H., Yarnell, J. W., .. . Lawlor, D. A. (2010). Comparison of the associations of body mass index and measures of central adiposity and fat mass with coronary heart disease, diabetes, and all-cause 
mortality: a study using data from 4 UK cohorts-. The American journal of clinical nutrition, 91(3), 547-556.

Thompson, D., Karpe, F., Lafontan, M., \& Frayn, K. (2012). Physical activity and exercise in the regulation of human adipose tissue physiology. Physiological reviews, 92(1), 157-191.

Trotter, M., \& Hixon, B. B. (1974). Sequential changes in weight, density, and percentage ash weight of human skeletons from an early fetal period through old age. The anatomical record, 179(1), 1-18.

VanItallie, T., Yang, M.-U., Heymsfield, S. B., Funk, R. C., \& Boileau, R. A. (1990). Heightnormalized indices of the body's fat-free mass and fat mass: potentially useful indicators of nutritional status. The American journal of clinical nutrition, 52(6), 953-959.

Wagenmakers, A. J. M. (2012). The Metabolic Systems: Protein and Amino Acid Metabolism in Muscle. In P. A. Farrell, M. J. Joyner, \& V. Caiozzo (Eds.), ACSM's Advanced Exercise Physiology (Second ed., pp. 423 - 446). Baltimore, MD: Lippincott Williams \& Wilkins.

Wang, Z. M., Heshka, S., Pierson, R. N., Jr., \& Heymsfield, S. B. (1995). Systematic organization of body-composition methodology: an overview with emphasis on component-based methods. Am J Clin Nutr, 61(3), 457-465.

Wang, Z. M., Ma, R., Pierson, R. N., Jr., \& Heymsfield, S. B. (1993). Five-level model: reconstruction of body weight at atomic, molecular, cellular, and tissue-system levels from neutron activation analysis. Basic Life Sci, 60, 125-128.

Wang, Z. M., Pierson, R. N., Jr., \& Heymsfield, S. B. (1992). The five-level model: a new approach to organizing body-composition research. Am J Clin Nutr, 56(1), 19-28.

Zemel, B., \& Barden, E. (2004). Measuring body composition. CAMBRIDGE STUDIES IN BIOLOGICAL AND EVOLUTIONARY ANTHROPOLOGY, 141-178. 